- едикаментозная терапия с точки зрения влияния на морфофункциональные характеристики эпидермального барьера

Петрунин Д. Д.

000 «ЛЕО Фармасьютикал Продактс»

125315, Российская Федерация, г. Москва, Ленинградский просп., д. 72, корп. 2

Различные медикаментозные средства наружной и системной терапии способны оказывать значительное влияние на морфологические и физиологические характеристики человеческого эпидермиса и его барьерные свойства, что может влиять на течение кожных заболеваний и эфорективность их лечения.

В данном обзоре литературы анализируются данные о влиянии различных классов лекарственных средств на морфофонкциональные характеристики эпидермального барьера и фрормулируются рекомендации, каким образом это может быть принято во внимание в клинической практике ведения пациентов с кожными заболеваниями.

Ключевые слова: эпидермальный барьер, эпидермальные липиды, корнеодесмосомы, плотные контакты, трансэпидермальная потеря воды

Конфликт интересов: Петрунин Д. Д. является сотрудником ООО «ЛЕО Фармасьютикал Продактс».

Для цитирования: Петрунин Д. Д. Медикаментозная терапия с точки зрения влияния на морфофункциональные характеристики эпидермального барьера. Вестник дерматологии и венерологии. 2019;95(1):59-76.

https://doi.org/10.25208/0042-4609-2019-95-1-59-76 


\title{
Dharmacotherapy: Its impact on morphofunctional characteristics of the epidermal barrier
}

\author{
Dmitry D. Petrunin
}

LEO Pharmaceutical Products, LLC

Leningradsky prospekt, 72, korpus 2, Moscow, 125315, Russian Federation

Various pharmaceuticals used for topical and systemic therapy are capable of exerting significant impact on morphological and physiological characteristics of human epidermis, as well as its barrier properties.

This may affect the course of dermatologic diseases and the efficacy of their treatment.

In this literature review, the author analyzes the impact of various pharmaceutical classes on the morphofunctional characteristics of the epidermal barrier and formulates recommendations for skin disease treatment.

Keywords: epidermal barrier, epidermal lipids, corneodesmosomes, tight junctions, transepidermal water loss

Conflict of interest: Dmitry D. Petrunin is an employee of LEO Pharmaceutical Products, LLC.

For citation: Petrunin D. D. Pharmacotherapy: Its impact on morphofunctional characteristics of the epidermal barrier. Vestnik Dermatologii i Venerologii. 2019;95(1):59-76. https://doi.org/10.25208/0042-4609-2019-95-1-59-76 


\section{Введение}

Сформировавшийся в ходе эволюционного развития перешедших к сухопутному образу жизни высших хордовых многослойный плоский ороговевающий эпителий, которым представлен эпидермис человека, является уникальной структурой, отражающей адаптацию к изменившейся среде обитания [1-3].

Ключевой функцией кожи как человеческого органа является фрормирование барьера между внутренней средой организма и агрессивным внешним окружением. Данный орган должен обеспечивать защиту организма от химических агентов, ультрафиолета, механических воздействий и патогенных микроорганизмов, но, что особенно важно, служить эффективным водонепроницаемым барьером, предотвращающим потерю воды и электролитов, без чего невозможно существование живых существ на суше [4].

Бытовавшее до середины XX века представление, что эпидермис является лишь нагромождением мертвых роговых чешуек, обеспечивающих механическую защиту [5], сегодня воспринимается лишь как исторический анекдот и анахронизм. Последующие исследования, в основу которых легла работа A.M. Kligman 1964 года [6], наглядно показали, сколь глубоко заблуждались авторы прошлых лет и веков, придерживаясь столь упрощенных взглядов на одну из самых сложных структур человеческого организма. Со временем кропотливое изучение человеческого эпидермиса привело к появлению целого раздела дерматологии, иногда называемого корнеологией [7] (т.е., в дословном переводе, науки, посвященной изучению рогового слоя эпидермиса). Только за период с 2000 по 2010 год было опубликовано свыше 500 работ на семи языках, посвященных человеческому эпидермальному барьеру [8].

Также за последние три десятилетия был аккумулирован большой массив данных о влиянии на те или иные параметры эпидермального барьера различных экзогенных факторов, включая наружную и системную медикаментозную терапию. О последнем аспекте и пойдет речь в данном обзоре.

\section{Общие представления о физиологии кожного барьера человека}

Эпидермис является «первым эшелоном обороны» человеческого организма, непосредственно контактирующим с внешней средой. Принято условно разделять его на 4 (на ладонях и подошвах, где присутствует дополнительный блестящий (stratum lucidum) слой - 5) слоя, отражающих последовательные этапы дифференцировки основной клеточной популяции эпидермиса кератиноцитов $[4,9,10]$. Самым глубоким является базальный слой, также именуемый зародышевым (stratum basale sed germinativum), представленный клетками с высоким митотическим индексом; далее в направлении поверхности выделяют шиповатый слой (stratum spinosum) и зернистый слой (stratum granulosum). Указанные слои представляют т. н. живую часть эпидермиса и имеют совокупную толщину 50-100 мкм, тогда как следующий за ними самый верхний слой эпидермиca, роговой (stratum corneum), имеет толщину 10-20 мкм и представляет неживую часть эпидермиса, т. к. состоит из мертвых роговых чешуек (корнеоцитов), являющихся терминальной стадией диффреренцировки корнеоцитов. На этой стадии данные клетки уплощаются, утрачивают ядро, их цитоплазма заполняется микрофибриллярным белком кератином, формируется роговой конверт, состоящий из структурных белков инволюкрина, лорикрина и других $[4,9,10]$.

Роговой слой эпидермиса насчитывает от 10 до 25 слоев корнеоцитов, ориентированных параллельно поверхности кожи и погруженных в липидный матрикс [11-13]. Предшественники липидов этого матрикса, а также ферменты для их процессинга содержатся в специализированных временных органеллах - ламеллярных (пластинчатых) тельцах (или, по автору, гранулах Одланда). Синтез ламеллярных телец начинается в дистальных отделах шиповатого слоя, созревание происходит в зернистом слое и в области перехода зернистого в роговой слой их содержимое путем экзоцитоза попадает во внеклеточное пространство, формируя липидный матрикс.

Для правильной организации липидного матрикса важны также т. н. липидные конверты корнеоцитов. Липидный конверт представляет собой монослой неполярных липидов, связанный эфирными связями с роговым конвертом (преимущественно с глутаминовыми группами инволюкрина). Данный липидный конверт служит своего рода «трафраретом», на основании которого формируются внеклеточные липидные слои [12-15].

Именно роговой слой эпидермиса и заполняющий его межклеточные пространства липидный матрикс обеспечивают барьерные свойства кожи, причем благодаря липидному матриксу вода и электролиты удерживаются в организме. Первые исследования в этой области, проведенные Gray и соавт. и в дальнейшем подтвержденные рядом других, продемонстрировали, что данный матрикс, составляющий около $10 \%$ массы рогового слоя, имеет уникальную ламеллярную структуру и химический состав, в который входят церамиды, холестерин и свободные жирные кислоты (СЖК) при очень низком содержании фоссфолипидов [9, 16].

Эти три категории липидов являются доминирующими в роговом слое и присутствуют в нем в примерно эквимолярном соотношении. Если же оценивать их соотношение в абсолютном массовом выражении, то доля церамидов, холестерина и СЖК в роговом слое эпидермиса составляет 50, 25 и $10 \%$ соответственно. Сбалансированное соотношение указанных компонентов принципиально важно для обеспечения структурной целостности и барьерных свойств рогового слоя. Данные липиды присутствуют в роговом слое как в виде межклеточного ламеллярного матрикса, так и будучи ковалентно связанными с роговым конвертом корнеоцитов, фоормируя упомянутый ранее липидный конверт [1, 17-19].

Помимо указанных, в роговом слое присутствуют еще два класса липидов, составляющих значительно меньшую долю, - сульфат холестерина и свободные сфингоидные основания. Сульфрат холестерина играет роль в процессе десквамации корнеоцитов; в случае генетического дефекта фермента, ответственного за его гидролиз (стероидной сульсратазы), развивается аутосомно-рецессивный генодерматоз - Х-сцепленный ихтиоз [20-22]. Свободные сфингоидные основания образуются в результате воздействия на церамиды ферментовцерамидаз и присутствуют во всей толще эпидермиса. Они являются важным фактором антимикробной защиты, а также участвуют в регуляции процессов кератинизации за счет ингибирования протеинкиназы C [23-25]. 
Липидный матрикс рогового слоя человеческого эпидермиса организован в уникальную ламеллярную структуру; было продемонстрировано, что липиды в межклеточных пространствах рогового слоя организованы в виде пластинок («ламелей»), представляющих собой бислои церамидов и наслоенных друг на друга наподобие пачки листов бумаги (рис. 1). Способность церамидов формировать бислои является их уникальным свойством, определяющим барьерные свойства эпидермиса. Будучи амфифильными липидами (т.е. имеющими в составе полярную (следовательно, гидрофрильную) головку и неполярный (гидрофробный) хвост), церамиды в роговом слое разворачиваются неполярной частью друг к другу, а полярной - наружу и, вытягиваясь в пространстве, фрормируют ламеллярные структуры [9, 26, 27]. Поскольку алифатические цепи («Хвосты») церамидов и связанных с ними ЖК представлены в большинстве своем неветвящимися длинноцепочечными насыщенными соединениями с высокой точкой плавления, образованный ими ламеллярный матрикс находится преимущественно в кристаллическом либо гелевом состоянии, что резко ограничивает возможность латеральной дифффузии и его проницаемость при фризиологической температуре [28]. Так, известно, что проницаемость для воды рогового слоя человеческого эпидермиса составляет всего 1/1000 от проницаемости других биомембран [29].

Очень важным с точки зрения фризиологии эпидермального барьера и, в частности, дифференцировки клеток эпидермиса фрактором является белок фрилаггрин, впервые выделенный из рогового слоя Steinert и соавт. (1981) [30]; его название представляет собой аббревиатуру, расшифровываемую как filament-aggregating protein - белок, связывающий филламенты. Он синтезируется в виде гигантского белка-предшественника, профилаггрина (>400 КДа), являющегося основным содержимым кератогиалиновых гранул, обнаруживаемых в зернистом слое эпидермиса. Далее, на поздних стадиях дифрференцировки, профилаггрин подвергается дефоссрорилированию и протеолизу с образованием множества мономеров фрилаггрина, которые связываются с промежуточными фриламентами кератина, что приводит к агрегации последних в макрофибриллы. Это дает возможность поперечной сшивки нитей кератина дисульфидными мостиками под воздействием ферментов-трансглутаминаз, в результате чего образуется плотный нерастворимый кератиновый матрикс, служащий каркасом для прикрепления белков рогового конверта и липидов, что в итоге приводит к формированию рогового слоя эпидермиса [31-33]. Далее выполнивший свою биологическую функцию филаггрин подвергается дальнейшему протеолизу с участием фрерментов-деиминаз и гистидаз, что приводит к образованию большого количества обладающих гигроскопическими свойствами аминокислот и их производных (пирролидонкарбоновая кислота, трансурокановая кислота), которые становятся основным компонентом естественного увлажняющего фактора (ЕУФ). ЕУФ - собирательное название для обладающих гигроскопичностью соединений, от которых зависят влагоудерживающие свойства эпидермиса [31, 33, 34]. Мутации гена фрилаггрина (FLG), а также снижение его экспрессии под влиянием некоторых медикаментозных средств играют важную роль в диссрункции эпидермального барьера и патогенезе ряда кожных заболеваний - атопический дерматит (АД), вульгарный ихтиоз и т. д. [31-33].

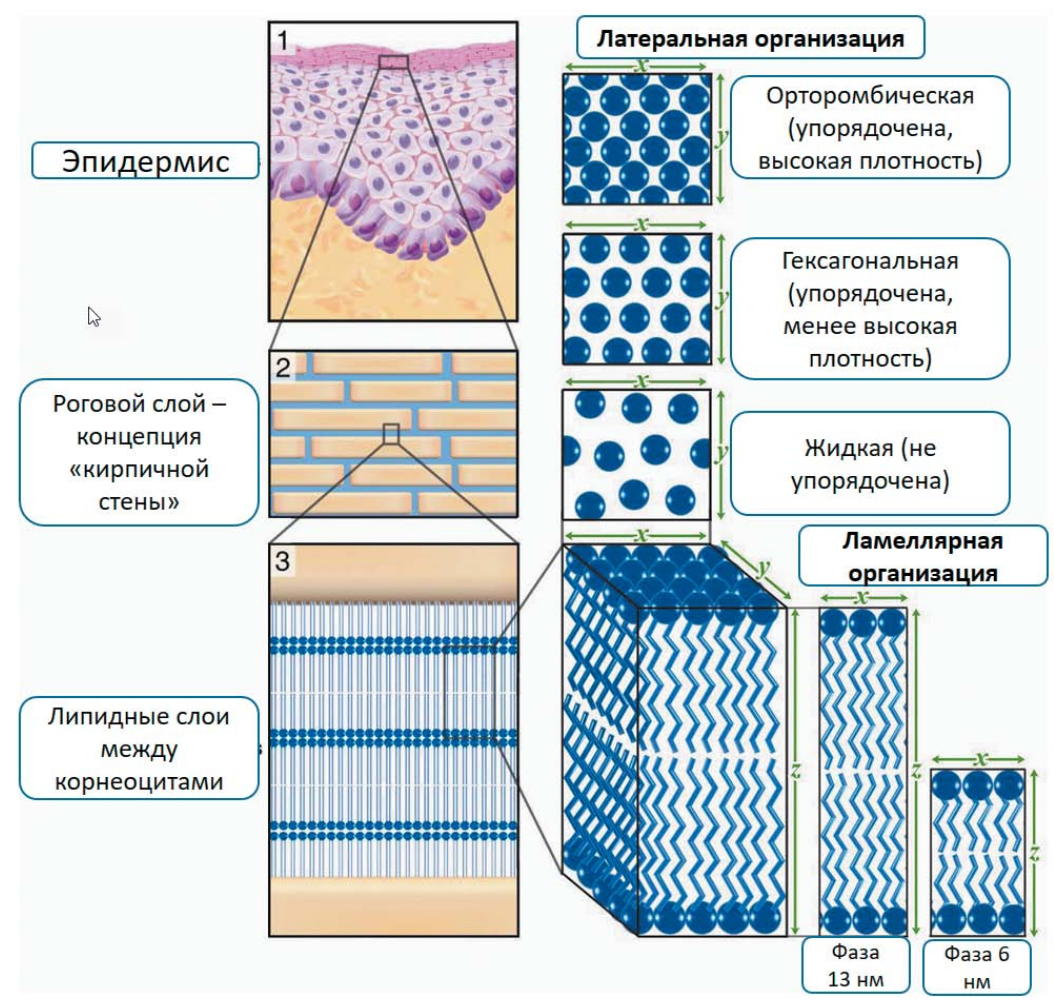

Примечание: изображение адаптировано на основании оригинального рисунка [35] Note: the image was adapted on the basis of the original picture [35] 
Также критическое значение для интегративности эпидермального барьера играют межклеточные контакты - корнеодесмосомы и плотные контакты. Основными межклеточными контактами клеток эпидермиса являются корнеодесмосомы (с базальной мембраной клетки базального слоя соединены полудесмосомами). Межклеточные десмосомальные контакты опосредуются белками-кадгеринами (десмоколлины, десмоглеины), которые связаны с фиксированными на клеточной мембране бляшками прикрепления, образованными белками плакоглобином, десмоплакином и плакофиллинами, а также внешними компонентами рогового конверта - корнеодесмозином, периплакином, энвоплакином, инволюкрином и казрином. С внутренней стороны с бляшкой прикрепления соединяются кератиновые филаменты. Корнеодесмосомы обеспечивают необходимую прочность и барьерные свойства эпидермиса, а также опосредуют передачу ряда межклеточных сигналов [36-39]. Мутации, приводящие к дефициту или отсутствию десмосомальных белков, ведут к тяжелым нарушениям эпидермального барьера, некоторые из них летальны [38-40]; выработка аутоантител к десмоглеинам 1 и 3 лежит в основе патогенеза таких тяжелых дерматозов, как вульгарная и листовидная пузырчатка $[41,42]$. В дистальных отделах рогового слоя корнеодесмосомы разрушаются ферментами - сериновыми протеазами (калликреины 5 и 7), что обеспечивает разделение роговых чешуек и их десквамацию [43].

В зернистом слое эпидермиса появляется новый важный тип межклеточного соединения - плотные контакты (англ. tight junctions). Как следует из их названия, какое-либо пространство между мембранами соседних клеток в зоне этих контактов отсутствует; белками, их формирующими, являются окклюдин и семейство клаудинов $[44,45]$. Помимо обеспечения необходимой когезии, плотные контакты играют крайне важную роль в предотвращении трансэпидермальной потери воды клаудин-1-десрицитные животные погибают в первый день жизни от тяжелого обезвоживания [46].

Ряд лекарственных средств могут влиять как на сами межклеточные контакты эпидермиса, так и на экспрессию белков, их фрормирующих.

Схематическое изображение корнеодесмосом и плотных контактов приводится на рисунке 2.

\section{Влияние различных средств наружной и системной терапии на эпидермальный барьер}

\section{Поверхностно-активные вещества и растворители}

В эмульсионных структурах, имеющих в своем составе водную и масляную фразы, сложно обойтись без применения эмульгаторов (поверхностно-активных веществ - ПАВ, они же сурфактанты). Дело в том, что подобные системы нестабильны и легко разделяются на составные части. Чтобы избежать этого, применяют эмульгаторы, которые представляют собой амфифрильную молекулу, имеющую гидрофильную и липофильную часть (рис. 3). В силу подобного строения данные молекулы скапливаются на границе раздела фраз и резко снижают поверхностное натяжение, в силу чего уменьшается вероятность конгломерации и сепарирования дисперсионной фразы (т.е. вещества, находящегося в виде мельчайших капель в т. н. непрерывной фазе, или дисперсионной среде).

Согласно существующей классификации, ПАВ разделяют на следующие типы (рис. 3):

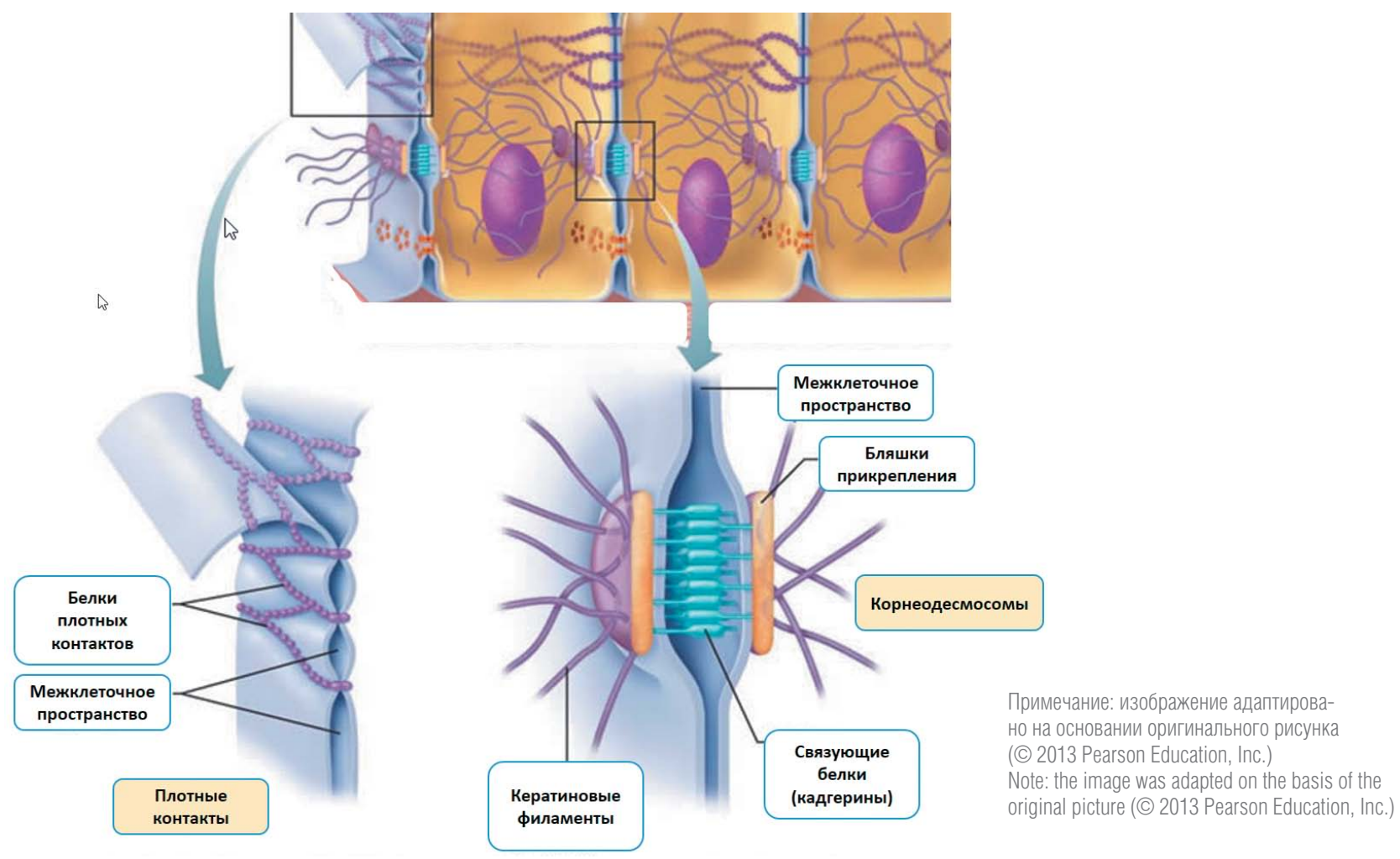

Рис. 2. Корнеодесмосомы и плотные контакть Fig. 2. Corneodesmosomes and tight junctions 


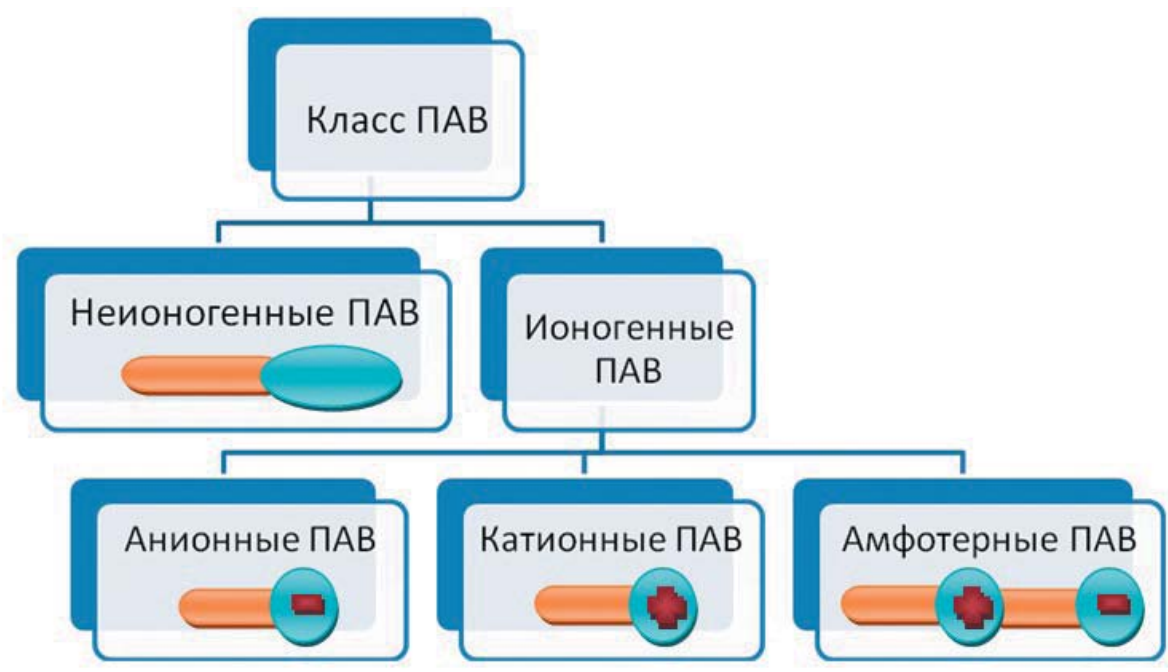

липофильная часть

1. Анионные эмульгаторы диссоциируют с образованием длинноцепочечных анионов, определяющих их эмульгирующее действие, при этом противоион также определяет их свойства. К этой группе относятся длинноцепочечные мыла (щелочные, металлические и органические) и сульфоэфриры (сульфраты и сульфронаты) жирных спиртов и этоксилатов спиртов: лаурилсульфат натрия, алкилбензосульфонат, додецилсульфонат натрия и т. д. Анионные ПАВ - это высокоэффрективные эмульгаторы, но при этом они являются наиболее частой причиной контактного дерматита [47], вызывают сильные повреждения липидного барьера рогового слоя, а потому относительно редко применяются в средствах наружной терапии и косметике, однако широко используются в моющих средствах.

2. Катионные эмульгаторы диссоциируют с образованием поверхностно-активного катиона, отличаются высокой гидрофильностью. К данной группе относятся амины и их соли, а также четвертичные аммониевые соединения (бензалкония хлорид, бензэтония хлорид). Как эмульгаторы катионные ПАВ менее эфрективны, чем анионные, однако также могут вызывать раздражение кожи и обладают большей цитотоксичностью. Последнее свойство позволяет в отдельных случаях использовать катионные эмульгаторы в качестве консервантов, однако в целом сейчас их применяют тоже очень редко.

3. Амфоотерные (цвиттерионные) эмульгаторы имеют гидрофильный радикал и гидрофробную часть, способную быть акцептором или донатором протона в зависимости от рН раствора и таким образом проявлять свойства анионных или катионных ПАВ. Важнейшими представителями амфотерных эмульгаторов являются фоссфолипиды, в частности фоссфатидилхолин (лецитин) и бетаины. С их помощью можно составлять рецептуры эмульсий и кремов, которые в зависимости от наличия воды имеют липофильный или гидрофильный характер. Амфотерные ПАВ малотоксичны, не обладают комедогенным эффректом и не раздражают кожу.

\section{4. Неионогенные эмульгаторы присутствуют} в водной среде в недиссоциированной фрорме (не образуют ионов), что дает им некоторые преимущества по сравнению с ионогенными - на их потребительские свойства не влияют электролиты, они химически индиффрерентны, не взаимодействуют с другими компонентами рецептуры. Хотя их эмульгирующая способность несколько уступает ионогенным, ведется поиск новых соединений с улучшенными показателями. Наиболее типичными представителями неионогенных эмульгаторов являются жирнокислотные эфиры макрогола, глицерина, сорбитана, сахарозы, а также стеролы (например, холестерин). Эти эмульгаторы приобретают в последнее время все большую популярность в силу их мягкости.

K патогенетическим механизмам отрицательного влияния ПАВ на характеристики эпидермального барьера можно, в частности, отнести эмульгирование и экстракцию липидов рогового слоя эпидермиса, что приводит к нарушению их организации и снижению количества; повреждение белков кожи - взаимодействие с кератинами с их денатурацией, набухание клеточных мембран и волокон коллагена, цитотоксическое действие и т. д. Одним из важных механизмов сегодня считается первичная гипергидратация рогового слоя, связанная с вызванным ПАВ нарушением вторичной и третичной структуры кератинов и обнажением новых связывающих воду участков, что приводит к гидратации мембраны. После испарения избытка воды способность ее связывать у денатурированного кератина резко снижается, что приводит к ухудшению барьерных свойств рогового слоя [49].

В литературе имеются многочисленные экспериментальные данные, подтверждающие описанное отрицательное влияние ПАВ на эпидермальный барьер. Например, K. Yanase и I. Hatta (2018) [50] изучили влияние додоцилсульфата натрия на структуру липидов эпидермиса при помощи синхротронной рентгеновской дифракции. Было установлено, что контакт с водным 
раствором данного ПАВ приводил к дезорганизации липидных ламелей с длинной периодичностью. До этого M. Xian и соавт. (2016) [51] продемонстрировали, что анионные ПАВ и коммерческие моющие средства нарушают целостность плотных соединений кератиноцитов.

Эти свойства ПАВ необходимо учитывать при выборе средств наружной терапии, а также средств для ухода и очищения кожи пациентов, страдающих различными дерматозами, т. к. использование агрессивных ПАВ (например, обычных моющих средств у атопиков или кремов со значительным содержанием водной фразы и эмульгаторов при хроническом процессе с выраженной сухостью) может привести к усугублению кожного процесса.

Органические растворители, в т. ч. спирты, влияют на эпидермальный барьер за счет растворения и экстракции липидов с поверхности кожи и из рогового слоя, что приводит к повышению трансэпидермальной потери воды и усилению пенетрации в кожу различных экзогенных соединений, а также оказывают раздражающее действие. Примеры: уайт-спирит, керосин, этанол, скипидар, ацетон. Указанные свойства органических растворителей продемонстрированы в ряде экспериментальных работ [52-54]; в частности, V. Goffin и соавт. [54] при помощи метода корнеоксенометрии установили, что с точки зрения влияния на структуру и функцию эпидермального барьера изученные растворители распределялись в порядке возрастания агрессивности следующим образом: гексан, этанол, метанол, смесь гексан-этанол, хлорофрорм, смесь хлороформ-метанол и смесь гексан-метанол.

С клинической точки зрения необходимо учитывать делипидизирующее и раздражающее действие спиртовых основ; препараты на их основе не следует применять при остром (усиление воспаления) и, напротив, хроническом (усугубление сухости) воспалении, а также у детей раннего возраста. Обращает на себя внимание, что основы ряда топических глюкокортикостероидных препаратов в форме лосьонов (Элоком ${ }^{\circledR}$, Белосалик ${ }^{\circledR}$ ) содержат изопропанол - низкомолекулярный спирт, по свойствам близкий к этиловому, а потому в той или иной мере обладают всеми указанными свойствами.

При этом не следует путать низкомолекулярные спирты с высшими жирными (цетиловый, цетостеариловый и т. д.) - последние не обладают свойствами растворителей, a, напротив, относятся к категории эмолентов.

\section{Топические глюкокортикостероиды и ингибиторы кальциневрина}

Первой линией и «золотым стандартом» терапии обострений множества воспалительных дерматозов являются топические глюкокортикостероиды (ТГКС).
Мощный противовоспалительный, иммуносупрессивный и антипролиферативный эфрфект ТГКС обусловливает эфффективность данного класса лекарственных средств у большинства дерматологических пациентов.

В то же время хорошо изучено выраженное отрицательное влияние наружной стероидной терапии, особенно при длительном применении, на морфофункциональные характеристики эпидермального барьера $[1,55]$. Активность модифицированных синтетических ТГКС во много раз превышает активность глюкокортикостероидов, синтезируемых в организме человека [56], а потому и их воздействие на эпидермальный барьер может быть гораздо более разрушительным. В частности, было продемонстрировано, что даже краткий курс сильных топических ГКС приводит к выраженным нарушениям эпидермального барьера [55].

J.S. Као и соавт. [55] установили, что применение 0,05 \% клобетазола пропионата дважды в день в течение всего трех дней приводит к выраженному (на $70 \%$ ) замедлению регенерации эпидермиса по сравнению с нормой, снижению продукции и секреции ламеллярных телец и уменьшению содержания липидов в межклеточном пространстве рогового слоя. При этом указанные нарушения барьерной функции и структурной целостности рогового слоя поддавались коррекции путем наружного применения смеси физиологических липидов (церамиды, холестерин, СЖК) в эквимолярном соотношении; это указывает, что описанные негативные изменения являются следствием подавляющего действия ТГКС на выработку эпидермальных липидов.

В исследовании L. Kolbe и соавт. [56] при помощи различных неинвазивных методик изучалось влияние на эпидермальный барьер наружной терапии 0,05 \% кремом клобетазола пропионата, наносившимся дважды в день на кожу предплечий 24 здоровых добровольцев женского пола в течение 3-4 недель. Было установлено, что применение клобетазола пропионата привело к значительному уменьшению толщины рогового слоя, размера клеток зернистого слоя (с $572 \pm 89$

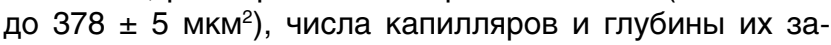
легания (в контрольной группе глубина составила $68 \pm$ 9 мкм, в группе, подвергшейся воздействию клобетазола, $-59 \pm 12$ мкм), очень выраженному истончению дермы по данным УЗИ ( $p<0,001$ по сравнению с исходным; причем наиболее выраженное уменьшение толщины дермы имело место в первую неделю применения ТГКС), а также значительному снижению всех липидных фракций эпидермиса (табл. 1).

H.M. Sheu и соавт. [57] провели исследование с участием 10 пациентов с атросрией кожи лица, вызванной терапией наружными стероидами. Bсе они длительно применяли различные ТГКС (в среднем 15 месяцев) и имели характерные проявления атрофии

Таблица 1. Влияние наружной терапии 0,05 \% клобетазола пропионатом на содержание липидов в роговом слое эпидермиса здоровых добровольцев

Table 1. Effect of the topical application of $0.05 \%$ clobetasol propionate on the lipid content in the cornified layer of healthy epidermis

\begin{tabular}{ccccccccc}
\hline Класс липидов* & Церамид 7 & Церамид 6 & Церамид 5 & Церамид 4 & Церамид 3 & Церамид 1 & Стеролы & СЖК \\
\hline $\begin{array}{c}\text { Уменьшение по сравнению } \\
\text { с исходным (\%), среднее } \pm \text { С0 }\end{array}$ & $29 \pm 11$ & $20 \pm 9$ & $38 \pm 7$ & $15 \pm 7$ & $35 \pm 6$ & $37 \pm 5$ & $30 \pm 20$ & $24 \pm 14$ \\
\hline
\end{tabular}

Примечание: * - содержание церамида 2 в данном эксперименте не удалось определить по техническим причинам

По данным Kolbe L. и соавт. [56]

Note: * - the content of ceramide 2 could not be determined in this experiment for technical reasons

In accordance with Kolbe L. et al. [56] 
эпидермиса - истонченная кожа с блестящей поверхностью, утрата кожного рисунка, дифрфузная эритема, телеангиоэктазии и т. д. Авторы провели сравнительный анализ биоптатов из очагов поражения и участков здоровой кожи (контроль) с помощью световой и электронной микроскопии, включая изучение криостатных срезов (срезы эпидермиса, подвергнувшиеся заморозке при сверхнизкой температуре с тетраоксидом рутения), а также показатели трансэпидермальной потери воды (ТЭПВ). Полученные результаты достаточно наглядны - число слоев рогового слоя кожи, подвергшейся воздействию ТГКС, составило 9,4 \pm 1,3, контрольных образцов $-18,0 \pm 1,2$ ( $<0,001)$, в опытных образцах также наблюдалось резкое снижение содержания и образования кератогиалиновых и ламеллярных гранул, содержания липидов (по данным полуколичественной денситометрии, 0,22 \pm 0,09 против 1,00 $\pm 0,22, p<0,001$ ) и уменьшение количества межклеточных липидных пластин. Эти изменения сопровождались выраженным

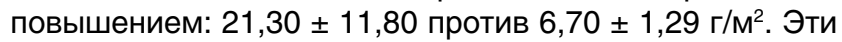
данные свидетельствуют о выраженном негативном Влиянии ТГКС на морфофункциональные характеристики эпидермального липидного барьера.

В еще одном исследовании К.M. Haapasaari и соавт. [58] изучали влияние наружной стероидной терапии на синтез коллагена с учетом содержания аминоконцевых пропептидов проколлагена I (PINP) и III (PIIINP) типа в эпидермисе 14 здоровых добровольцев, в течение одной недели дважды в день наносивших различные мази ТГКС и плацебо (контроль). Было установлено, что через 7 дней применения гидрокортизона и бетаметазона содержание PINP снизилось на 35 и $69 \%$, a PIIINP - на 35 и 62 \% соответственно, что говорит о развитии атрофических изменений уже в течение первой недели применения ТГКС.

Применение ТГКС оказывает выраженное негативное влияние не только на синтез и структуру эпидермальных белков и липидов, но и других важных компонентов межклеточного матрикса - мукополисахаридов (гликозаминогликанов). Так, в исследовании C. Gebhardt и соавт. [59] после внесения в культуру клеток фибробластов и НаСаТ кератиноцитов $150 \mathrm{HM}$ дексаметазона через 24 часа отмечалось выраженное, почти двукратное снижение гиалуронана - ключевого гликозаминогликана человеческой кожи, участвующего в процессах тканевого гомеостаза, пролиферации клеток, гидратации эпидермиса и репарации $(\mathrm{p}=0,027$ для фрибробластов и $\mathrm{p}=0,015$ для кератиноцитов), причем первые признаки снижения отмечались уже через 3 часа. Полученные данные были подтверждены результатами исследования in vivo, в рамках которого $0,1 \%$ мазь дексаметазона наносилась на кожу здоровых добровольцев трижды в день в течение 3 дней, что повлекло резкое снижение гиалуронана в полученных после этого биоптатах.

Эти результаты перекликаются с более ранними исследованиями - например, в исследовании W. Zhang и соавт. [60] было продемонстрировано, что внесение В культуру фрибробластов дермы $10^{-6}$ дексаметазона приводило к почти полной - на 97-98 \% супрессии экспрессии мРНК гиалуронансинтазы, причем данный эффрект развивался очень быстро: через 1 час после внесения стероида экспрессия HAS2 составляла $28 \%$ от контрольной, а через 2 часа - 1,2\%.
Таким образом, отрицательное влияние ТГКС на эпидермальный барьер не только затрагивает различные структуры кожи, но и отмечается уже в начале применения препаратов, что должно учитываться при назначении терапии.

В одной из работ Н. Saarni и соавт. [61] продемонстрировали, что даже в очень низкой концентрации ГКС угнетают синтез гиалуроновой кислоты фибробластами - в концентрации $10^{-10}$ гидрокортизона бутирата и бетаметазона валерата снижение составило 50 и $95 \%$ соответственно. При этом отмечено, что для подавления синтеза гиалуроновой кислоты требуются концентрации стероидов, в 100-1000 раз меньшие, чем необходимые для ингибирования синтеза коллагена.

Одним из вариантов решения проблемы может быть переход после уменьшения первичной остроты процесса с ТГКС на другой класс наружных противовоспалительных средств, не обладающий описанными для ТГКС неблагоприятными эфффектами в отношении эпидермального барьера - сегодня таковым классом являются топические ингибиторы кальциневрина, в перспективе еще одной альтернативой могут стать топические ингибиторы янус-киназ.

В многочисленных клинических исследованиях было продемонстрировано, что наиболее активный представитель класса ингибиторов кальциневрина, такролимус (Протопик ${ }^{\circledR}$ мазь) по клинической эфффективности сопоставим с сильными ТГКС и превосходит ТГКС слабой и умеренной активности [62], при этом, в отличие от стероидов, оказывая положительный эффект на параметры эпидермального барьера.

Так, H. Kyllonen и соавт. [63] провели открытое исследование влияния длительной интермиттирующей терапии мазью такролимуса и ТГКС на синтез коллагена и толщину эпидермиса. В исследовании приняли участие 2 группы пациентов, из которых 56 в течение 12 месяцев получали интермиттирующие курсы лечения мазью такролимуса 0,1\%, а 36 - ТГКС IIII класса активности по той же схеме. Контрольную группу составили здоровые добровольцы. Исходно и через 12 месяцев лечения у участников определялись уровни пропептидов коллагена I (PINP) и III (PIINP), а также толщина эпидермиса при помощи УзИ (DUB20-S; Tabernapro medicum, Люнебург, Германия; 30 МГц, 8 точек). Через 12 месяцев в группе, получавшей лечение мазью такролимуса, толщина эпидермиса увеличилась на 114,7 мкм $(+9,0 \%$, p < 0,001), тогда как в группе, получавшей ТГКС, уменьшилась на 110,7 мкм $(-8,2 \%$, р $<0,001)$ (рис. 4). При использовании такролимуса совокупный уровень PINP и PIIINP возрос на 272,0 мкг/л (+149,9\%, p < 0,001); для сравнения, в группе, получавшей ТГКС, этот показатель увеличился лишь на 11,0 мкг/л (+3,9\%, статистически не значимо) (табл. 2). Эти данные свидетельствуют об отсутствии атрофогенного действия и инициации репаративных процессов в эпидермисе на фоне терапии мазью такролимуса.

Примечательно, что в группе, получавшей лечение Протопиком, были 3 пациента, у которых на фроне длительной предшествующей стероидной терапии имелись признаки атрофии кожи. Через 12 месяцев лечения у всех трех пациентов наблюдалось увеличение синтеза коллагена, толщины кожи и устранение визуальных симптомов атрофии. 
150

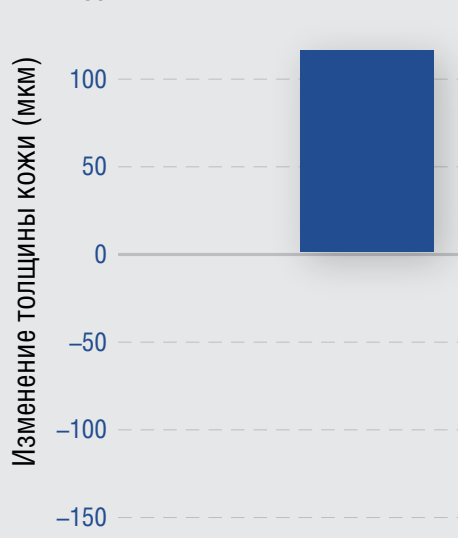

$\bar{p}<\overline{0.001}$

- Мазь такролимуса $0,1 \%(n=44)$

- TГKC $(n=30)$

Рис. 4. Влияние длительной (12 месяцев) интермиттирующей терапии мазью такролимуса (Протопик ${ }^{\circledR}$ и ТГКС на толщину кожи

Fig. 4. Effect of long-term (12 months) intermittent therapy with tacrolimus ointment (Protopic ${ }^{\circledast}$ ) and topical corticosteroids on skin thickness

Таблица 2. Совокупный уровень пропептидов коллагена PINP и PIIINP, мкг/л Table 2. Overall level of collagen propeptides PINP and PIIINP, $\mu \mathrm{g} / \mathrm{l}$

\begin{tabular}{|c|c|c|}
\hline Группа & Исходно & Через 12 месяцев \\
\hline $\begin{array}{c}\text { Мазь такролимуса } \\
\left(П р о т о п и \kappa^{\circledR}\right)(n=56)\end{array}$ & 193,0 & $465,0(+149,9 \%, p<0,001)$ \\
\hline TГKC $(n=36)$ & 285,0 & 296,0 (+3,9\%, не значимо) \\
\hline Контроль $(\mathrm{n}=27)$ & 515,0 & ND \\
\hline
\end{tabular}

Позднее указанные результаты получили подтверждение в исследовании А.Л. Бакулева и соавт. [64]. Под наблюдением находились 60 пациентов с атопическим дерматитом, из которых 22 получали лечение мазью Протопик ${ }^{\circledR} 0,1 \% 1$ раз в день в течение 14 дней, а 38 мазью метилпреднизолона ацепоната по той же схеме. Наряду с клинической оценкой проводилось исследование кожи с помощью цифровой ультразвуковой системы высокого разрешения DUB (TPMGmbH, Германия; 33 МГц, разрешение 78 мкм). Клиническая эффрективность терапии была высокой в обеих группах и не имела статистических различий ( $p \geq 0,05)$. Данные УЗИ после лечения у больных, получавших ТГКС и Протопик ${ }^{\circledR}$, имели существенные различия. В частности, снижение абсолютных значений толщины дермы после лечения метилпреднизолона ацепонатом в сравнении с контрольными значениями ( $p<0,001)$, зарегистрированное у данной группы, свидетельствовало о наличии субклинических атрофрических процессов в дерме. Применение Протопика характеризовалось ультрасонографическими признаками нормализации плотности эпидермиса и дермы, что говорит о мощном противовоспалительном действии данного препарата в различных слоях кожи, вовлеченных в патологический процесс; при этом толщина дермы соответствовала контрольным значениям данного показателя и была выше абсолютных цифр, зарегистрированных у лиц, получавших метилпреднизолона ацепонат ( $<<0,001)$, что свидетельствует об отсутствии атрофрогенного действия такролимуса, характерного для ТГКС, включая препараты умеренной активности (метилпреднизолона ацепонат).

В дальнейшем схожие результаты были получены с использованием конфрокальной микроскопии в иссле- довании A. Jiráková и соавт. [65], в котором приняли участие 45 пациентов с атопическим дерматитом: 1 группа $(n=23)$ в течение 3 месяцев 1 раз в день наружно применяла метилпреднизолона ацепонат, а вторая $(\mathrm{n}=22)$ - мазь Протопик ${ }^{\circledR}$ дважды в день в течение того же срока. В группе, получавшей метилпреднизолона ацепонат, отмечалось заметное и статистически значимое снижение толщины эпидермиса, чего не наблюдалось в группе, получавшей такролимус. Кроме того, в шиповатом слое эпидермиса пациентов из группы, получавшей ТГКС, была увеличена доля кератиноцитов с измененной формой.

В исследовании J. Chittock и соавт. [66] 17 добровольцев с атопическим дерматитом в фазу ремиссии в течение 8 недель дважды в неделю наносили 0,1\% мазь такролимуса и 0,1 \% крем бетаметазона валерата на внутреннюю поверхность правого и левого предплечья соответственно. Оцениваемыми параметрами были трансэпидермальная потеря воды, показатели инфракрасной денситометрии, рН поверхности кожи, электрическая емкость и протеазная активность в роговом слое эпидермиса. После завершения 8-недельного курса проводилась оценка нарастания ТЭПВ при последовательном удалении слоев клеток рогового слоя эпидермиса при помощи липкой ленты (20 повторений). Применение Протопика приводило к значительно более медленному нарастанию данного по-

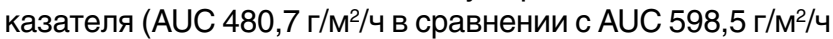
для бетаметазона валерата (p < 0,01) и AUC 579,2 г/м²/4 для не подвергавшихся лечению участков кожи, а также значительному снижению ТЭПВ в сравнении с исходным значением ( $p<0,0001)$, что говорит о благоприятном влиянии терапии такролимусом на структуру рогового слоя. ТГКС при применении по данной схеме (2 раза в неделю в течение 8 недель) не оказал значимого влияния на этот параметр. Также бетаметазона валерат оказывал выраженное негативное влияние на когезию (межклеточные связи) клеток рогового слоя по данным денситометрии. В группе пациентов, применявших Протопик $^{\circledR}$, наблюдалось достоверное повышение электрической емкости эпидермиса и превосходство по данному параметру перед ТГКС $(\mathrm{p}<0,05)$ и исходным значением ( $<<0,01) ; 43,35 \pm 1,45,40,76 \pm 1,47$ и 37,29 $\pm 1,23$ относительных единиц емкости. Терапия ТГКС приводила 
к значительно большему повышению $\mathrm{pH}$ поверхности кожи в сравнении с такролимусом $(5,34$ и 5,20; $><0,01)$ и с исходным значением $(5,10 ; p<0,001)$, что снижает активность сорингомиелиназы и бета-глюкоцереброзидазы (ключевых для биосинтеза церамидов фрерментов) и таким образом приводит к нарушению структуры межклеточных липидных мембран и, вследствие этого, барьерной функции эпидермиса $[1,67]$.

Особый интерес представляют данные о протеолитической активности в роговом слое, полученные в данном исследовании. Оценивались химотрипсинподобная (калликреин-7) и трипсин-подобная (калликреины 5 и 14) протеазные активности. Было установлено, что на фроне терапии мазью Протопик ${ }^{\circledR}$ происходило снижение всех трех типов протеолитической активности, причем для казеинолитической и трипсин-подобной это снижение было статистически значимым, тогда как терапия ТГКС сопровождалась тенденцией к повы-

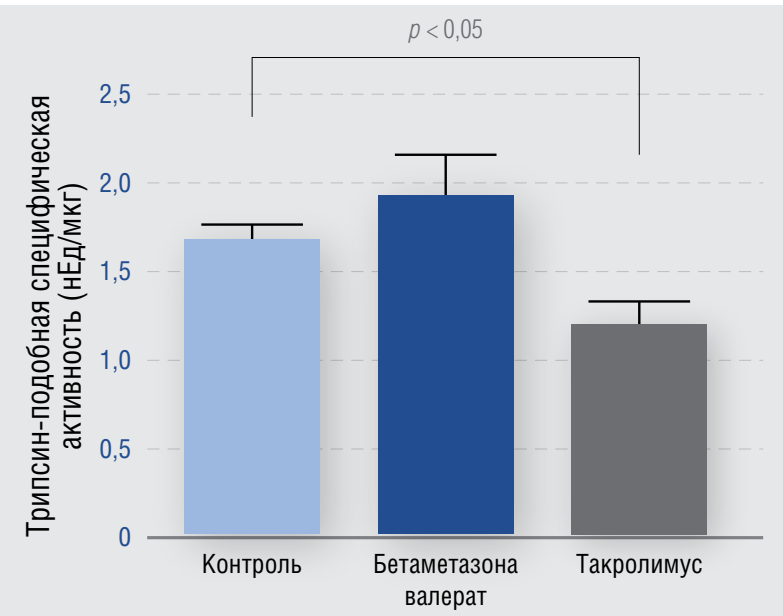

Рис. 5. Влияние 8-недельной терапии 2 раза в неделю мазью такролимуса (Протопик ${ }^{\circledR}$ ) и бетаметазона валерата на трипсин-подобную активность в роговом слое

Fig. 5. Effect of 8-week treatment (2 times a week) with tacrolimus ointment (Protopic ${ }^{\circledR}$ ) and betamethasone valerate on trypsin-like activity in the cornified layer шению данного показателя, что еще раз подчеркивает отрицательное влияние ТГКС на морфофункциональные показатели эпидермального барьера (рис. 5).

В исследовании S. Dahnhardt-Pfeiffer и соавт. [68] было продемонстрировано, что при использовании 0,1 \% мази Протопик ${ }^{\circledR}$ и 0,1 \% крема мометазона фуроата у пациентов с АтД в фразе обострения противовоспалительная терапия указанными препаратами через 10 дней приводила к увеличению содержания липидов в роговом слое в обеих группах, однако в группе, получавшей такролимус, оно было гораздо более выраженным, чем в группе, получавшей мометазона фруроат. По данным трансмиссионной электронной микроскопии, при использовании мометазона протяженность липидных мембран в межклеточном пространстве

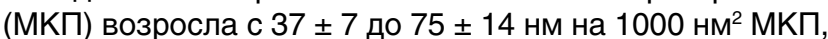
а при использовании такролимуса - с $40 \pm 5$ до $155 \pm$

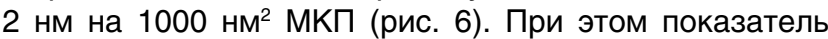
увлажненности рогового слоя при использовании такролимуса (Протопика) значительно возрос, а при использовании мометазона не претерпел изменений.

Также представляет интерес исследование S.E. Lee и соавт. [28], в рамках которого изучалось влияние 10-дневной терапии 0,05 \% мазью клобетазола пропионата и 0,1 \% мазью такролимуса на плотные контакты эпидермоцитов мышиной кожи. При помощи конфрокальной иммунофлуоресценции, вестерн-блоттинга и ПЦР в реальном времени оценивались структура и содержание ключевых белков плотных контактов - клаудинов 1 и 4 и окклюдина. Аппликации клобетазола пропионата приводили к выраженному нарушению структуры и снижению содержания всех трех белков, тогда как мазь такролимуса не оказывала влияния на клаудины 1 и 4 и приводила к снижению содержания окклюдина в меньшей степени, чем клобетазол. При этом применение клобетазола сопровождалось истончением эпидермиса, снижением плотности коллагена и повышением ТЭПВ, чего не наблюдалось при применении Протопика.

Сводные данные о влиянии терапии ТГКС и Протопика на различные параметры эпидермального барьера приводятся в таблице 3.

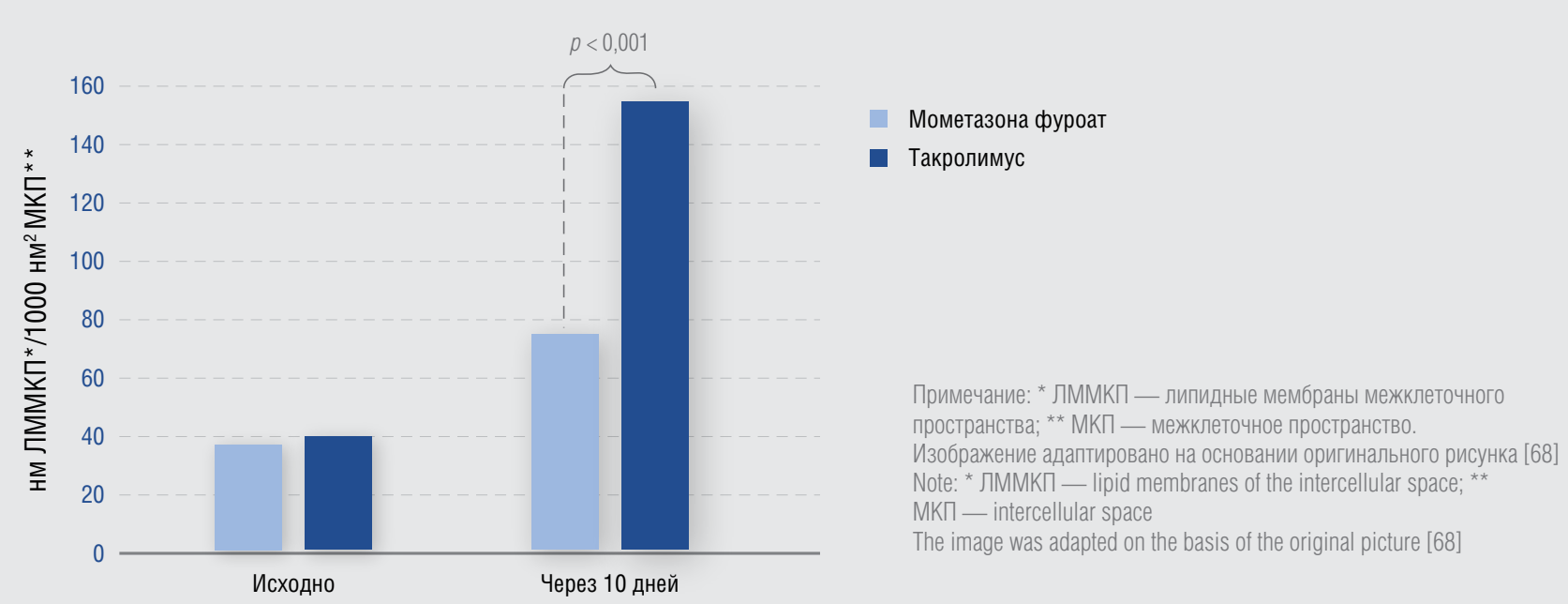

Рис. 6. Влияние терапии мометазона фуроатом и такролимусом (Протопик ${ }^{\circledR}$ ) на протяженность липидных мембран в межклеточных пространствах рогового слоя пациентов с атопическим дерматитом Fig. 6. Effect of treatment with mometasone furoate and tacrolimus (Protopic ${ }^{\circledR}$ ) on the length of lipid membranes in the intercellular spaces of the cornified layer in patients with atopic dermatitis 
Таблица 3. Влияние терапии ТГКС и такролимусом (Протопик ${ }^{\circledR}$ ) на различные параметры эпидермального барьера

Table 3. Effect of treatment with topical corticosteroids and tacrolimus (Protopic ${ }^{\oplus}$ ) on different parameters of the epidermal barrier

\begin{tabular}{|c|c|c|c|}
\hline Свойство & Метод/параметр & ТГKC & Такролимус \\
\hline Структура и толщина эпидермиса & $\mathrm{OKT}^{*}$ & Отрицательно & Тенденция к положительно \\
\hline Структура и толщина эпидермиса & узи & Отрицательно & Положительно \\
\hline Структура и толщина эпидермиса & Синтез коллагена & Отрицательно & Положительно \\
\hline Целостность и когезия рогового слоя & Удаление липкой лентой / ТЭПВ & Отрицательно & Положительно \\
\hline Целостность и когезия рогового слоя & Белки плотных контактов & Отрицательно & Нейтрально / отрицательно < ТГКС \\
\hline Протеолитическая активность в роговом слое & Активность протеаз & Отрицательно & Положительно \\
\hline Эфрфект на рН & рН-метрия & Отрицательно & Положительно \\
\hline Гидратация & Проводимость/корнеометрия & Положительно & Положительно \\
\hline Липидные пластины & Биопсия/ТЭМ** & Положительно & Положительно > ТГКС \\
\hline Нарушение диффференцировки & Филаггрин и Na-ПKK*** & Отрицательно & Нейтрально / положительно \\
\hline Экспрессия антимикробных пептидов & ИФА $A^{* \star *}$ & Отрицательно & Нейтрально / положительно \\
\hline
\end{tabular}

Примечание: * ОКТ — оптическая когерентная томограсфия; ** ТЭМ — трансмиссионная электронная микроскопия; *** Na-ПКК — пирролидонкарбонат натрия; **** ИФА — иммуноферментный анализ

На основании источников [13, 15-17, 22-25, 28-31]

Note: * OKT — optical coherence tomography; ${ }^{* \star}$ TЭM — transmission electron microscopy; ${ }^{* * \star}$ Na-ПKK — sodium pyrrolidone carbonate; ${ }^{* * \star *}$ ИФA — enzyme-linked immunosor-

bent assay

In accordance with [13, 15-17, 22-25, 28-31]

Обращает на себя внимание, что появившийся в России генерический препарат мази такролимуса местного производителя может не обладать эквивалентным оригинатору положительным влиянием на морфоорункциональные характеристики эпидермального барьера, поскольку в нем, в отличие от оригинального препарата (мази Протопик ${ }^{\circledR}$ ) присутствует водная фаза и по этой причине используется эмульгатор - эмульсионный воск, а также консерванты. О негативном влиянии эмульгаторов (ПАВ) на характеристики эпидермального барьера см. выше.

С учетом вышеизложенного может быть сфрормулирован новый подход, позволяющий рационализировать наружную терапию такого дерматоза, как атопический дерматит [69]. Его задачей является выход из порочного круга, когда усугубление нарушения эпидермального барьера под действием стероидной терапии предрасполагает к постоянно рецидивирующему течению дерматоза. Поскольку мазь Протопик ${ }^{\circledR}$ по своей противовоспалительной активности не уступает сильным ТГКС, но, в отличие от последних, способствует восстановлению эпидермального барьера, то с точки зрения клинического мышления выглядит оправданным перевод пациента с ТГКС на указанный препарат. Однако использованию мази такролимуса как препарата стартовой терапии при выраженном обострении АД препятствуют 2 фрактора. Первый - побочный эфффект в виде жжения, наблюдаемый в первые дни лечения такролимусом [70]. При выраженном воспалении данный побочный эффеккт может усугубиться. Второй - лекарственной формой такролимуса является мазь, которая не является оптимальной при остром воспалении.

В связи с этим рациональной представляется схема, в рамках которой стартовой терапией является ТГКС (монокомпонентный либо, при наличии признаков вторичного инфицирования, комбинированный). Далее, по мере стихания островоспалительных симптомов (в среднем через \pm 7 дней), осуществляется перевод на мазь Протопик ${ }^{\circledR}$ и лечение продолжается до полного купирования обострения. Если АД имеет тяжелое течение с частотой обострений 4 и более в течение года, после достижения ремиссии рационально рекомендовать проактивную терапию мазью такролимуса (аппликации 2 раза в неделю) с целью пролонгации межрецидивного периода. При возникновении первых признаков обострения возможен перевод на ежедневное использование такролимуса. Разумеется, на всех этапах ведения пациента с АД показано применение эмолентов. Описанная схема лечения отражена на рис. 7.

\section{Витамины и витаминоподобные соединения}

Витамин $\mathrm{D}_{3}$ (холекальциферол), наряду с его жизненно важным значением для организма человека в целом, играет важнейшую роль в физиологии человеческой кожи, регулируя процессы диффееренцировки и пролиферации кератиноцитов и локальный иммунный ответ. Холекальциферол (витамин $\mathrm{D}_{3}$ ) - предшественник активной фрормы витамина $D_{3}$, кальцитриола (1a25-дигидроксивитамин $\mathrm{D}_{3}$ ), либо синтезируется в коже путем неэнзиматической реакции под воздействием УФ-лучей из 7-дегидрохолестерина, либо поступает в организм алиментарно. Обращает на себя внимание, что в кератиноцитах человеческой кожи экспрессируются фрерменты (СҮР27A1 - 25-гидроксилаза, и СҮР27B1 - 1а-гидроксилаза), необходимые для транссрормации холекальциферола в активный метаболит $1,25\left(\mathrm{OH}_{2}\right) \mathrm{D}$, который непосредственно защищает кожу от УФ-повреждения и малигнизации [71-74].

В коже наблюдается высокая экспрессия рецептора витамина D - VDR, при этом не все эффректы опосредованы его лигандом 1,25( $\left.\mathrm{OH}_{2}\right) \mathrm{D}$. Tak, VDR и $\beta$-катенин необходимы для перехода волос из фразы телогена (покоя) в фразу анагена (роста). 1,25( $\left(\mathrm{OH}_{2}\right)$ D в коже оказывает антипролиферативное действие и усиливает диффреренцировку кератиноцитов, а также ряд других эффоектов. Taк, 1,25( $\left(\mathrm{OH}_{2}\right)$ D индуцирует в кератиноцитах синтез 
ТГКС (моно- или комбинированные)

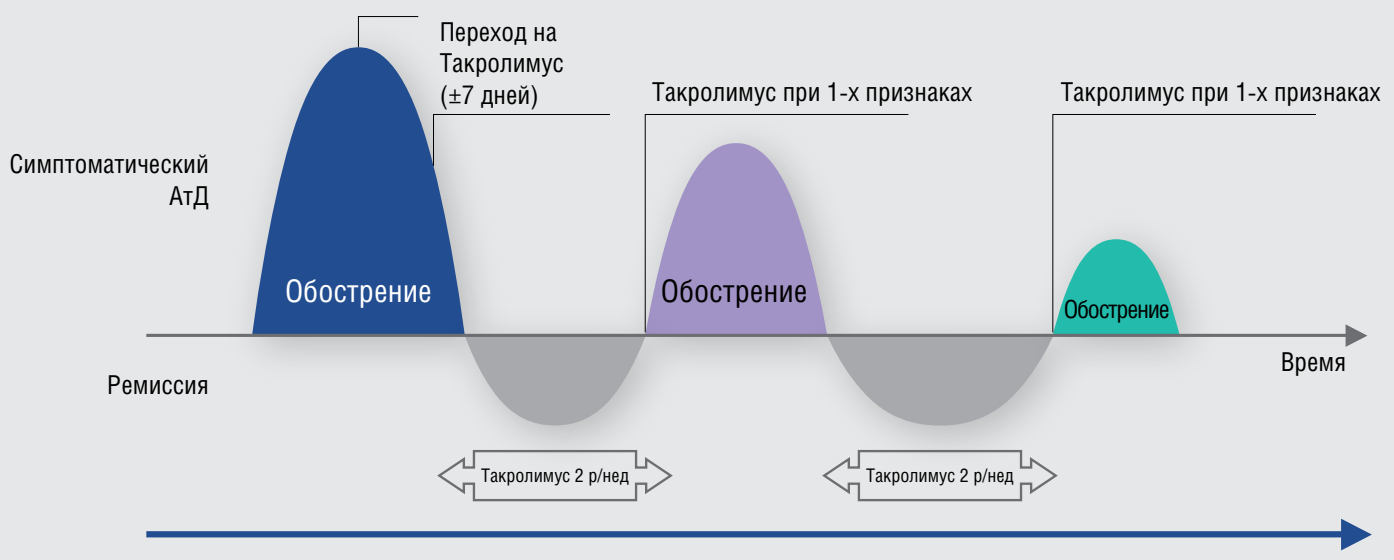

Рис. 7. Холистический подход к ведению пациентов с АД с переходом с ТГКС на мазь такролимуса с целью компенсации негативного влияния ТГКС на эпидермальный барьер и предупреждения новых обострений [69]

Fig. 7. A holistic approach to treating patients with atopic dermatitis (with a transition from topical corticosteroids to tacrolimus ointment in order to compensate for the negative impact of topical corticosteroids on the epidermal barrier and to prevent new exacerbations) [69]

каспазы-14 (САSP14) - важного для диффреренцировки фрермента, а также генов эпидермального комплекса дифрференцировки (LCE-1D, -1F, -2B). 1,25(ОН $\left.\mathrm{OH}_{2}\right) \mathrm{D}$ усиливает продукцию кателицидина и некоторых десензинов кератиноцитами, таким образом усиливая защиту от инфекции. Наконец, 1,25( $\left.\mathrm{OH}_{2}\right) \mathrm{D}$ стимулирует экспрессию ряда связанных с кератином транскриптов, а также поздних белков рогового конверта (LCE - Late Cornified Envelope), таким образом способствуя формированию эпидермального барьера [71-74].

В отношении иммунной системы 1,25 $\left(\mathrm{OH}_{2}\right) \mathrm{D}$ стимулирует врожденное звено, в частности продукцию АМП, В т. ч. кателицидина; но при этом ограничивает активность адаптивного звена - угнетает продукцию ИЛ-17 (вероятно, снижая при этом риск аутоиммунных заболеваний - ассоциация с десицитом витамина D была продемонстрирована для СД1, рассеянного склероза и ревматоидного артрита), обладает противовоспалительным действием за счет снижения экспрессии NFKB и СОХ2. Кальцитриол подавляет экспрессию АПК ИЛ-1, ИЛ-6, ИЛ-12 и ФНО-а, а также МНС-ІІ и костимулирующих молекул (CD40, CD80/86), что приводит к угнетению Th1 и Th17-ответа и индукции T-reg и Th2 клеток, а также продукции ИЛ-10. Кроме того, кальцитриол ингибирует продукцию Т-клетками ИЛ-2, а также дифференцировку и продукцию антител В-лимфоцитами [71-74].

Для лечения кожных заболеваний, прежде всего псориаза, были созданы аналоги витамина D, имеющие схожее влияние на усиление диффреренцировки и угнетение пролиферации кератиноцитов, иммуномодулирующий и противовоспалительный эффект, но отличающиеся многократно меньшим влиянием на метаболизм кальция, что позволяет применять их без риска гиперкальциемии и резорбции костной ткани. Так, влияние на метаболизм кальция и костной ткани наиболее часто применяемого для лечения псориаза аналога витамина D, кальципотриола, от 100 до 200 раз меньше, чем у исходного витамина [75].

Кальципотриол в виде монокомпонентных (Дайвонекс $^{\circledR}$ ) наружных препаратов и в комбинации с бетаметазона дипропионатом (мазь Дайвобет ${ }^{\circledR}$, гель Ксамиол ${ }^{\circledR}$, пена Enstilar ${ }^{\circledR}$ - последний препарат не зарегистриро- ван в РФ) является препаратом первой линии для лечения псориаза, одним из немногих, имеющих наивысший уровень доказательности с позиции доказательной медицины - 1a [76]. С точки зрения влияния на эпидермальный барьер особый интерес представляют именно комбинированные препараты кальципотриола и бетаметазона дипропионата: Дайвобет ${ }^{\circledR}$, Ксамиол $^{\circledR}$; помимо того что они обладают более высокой эфффективностью, чем ТГКС или кальципотриол в виде монотерапии, наличие в составе кальципотриола позволяет в значительной мере нивелировать негативное влияние стероида на характеристики эпидермального барьера [77]. Так, в исследовании Н. Norsgaard и соавт. (2014) [78], проведенном на культурах фрибробластов дермы, биоптатах человеческой кожи и минипигах, было продемонстрировано, что кальципотриол противодействует индуцируемой бетаметазоном супрессии синтеза коллагена I типа и гиалуроновой кислоты, оказывает разнонаправленное с бетаметазоном действие на экспрессию матриксных металлопротеиназ и предотвращает индуцируемое бетаметазоном истончение эпидермиса. В свою очередь, присутствие глюкокортикостероида способно отчасти нивелировать такие побочные эффекты кальципотриола, как периочаговое раздражение кожи, жжение и эритему [77].

Влияние ТГКС и кальципотриола на различные параметры кожного барьера систематизировано в таблице 4.

Еще одним важнейшим классом лекарственных средств, применяемых в дерматологии, являются производные витамина А - ретиноиды. Они применяются наружно для лечения акне (адапален, тазаротен) и некоторых других дерматозов и системно для лечения тяжелых форм акне, розацеа (изотретиноин), а также различных дискератотических нарушений (ацитретин, алитретиноин) [79]. Системная терапия изотретиноином приводит к выраженным нарушениям эпидермального барьера, включая когезию кератиноцитов и липидный профиль, в связи с чем получающим подобную терапию пациентам требуются коррективные меры [80]. В то же время в исследовании J.M. Jungersted и соавт. [81], в рамках которого у 8 пациентов с хронической экземой кистей рук, 
Таблица 4. Влияние терапии ТГКС и кальципотриолом /КПТ/ (Дайвонекс ${ }^{\circledR}$ ) на различные параметры кожного барьера, а также клинические эффректы комбинированной терапии (Дайвобет ${ }^{\circledR}$, Ксамиол $^{\circledR}$, Enstilar®)

Table 4. Effect of treatment with topical corticosteroids and calcipotriol / CPT / (Daivone $\left.{ }^{\circledR}\right)$ on various parameters of the skin barrier, as well as clinical effects of combined therapy (Daivobet ${ }^{\circledast}$, Xamiol $^{\circledR}$, Enstilar $^{\circledR}$ )

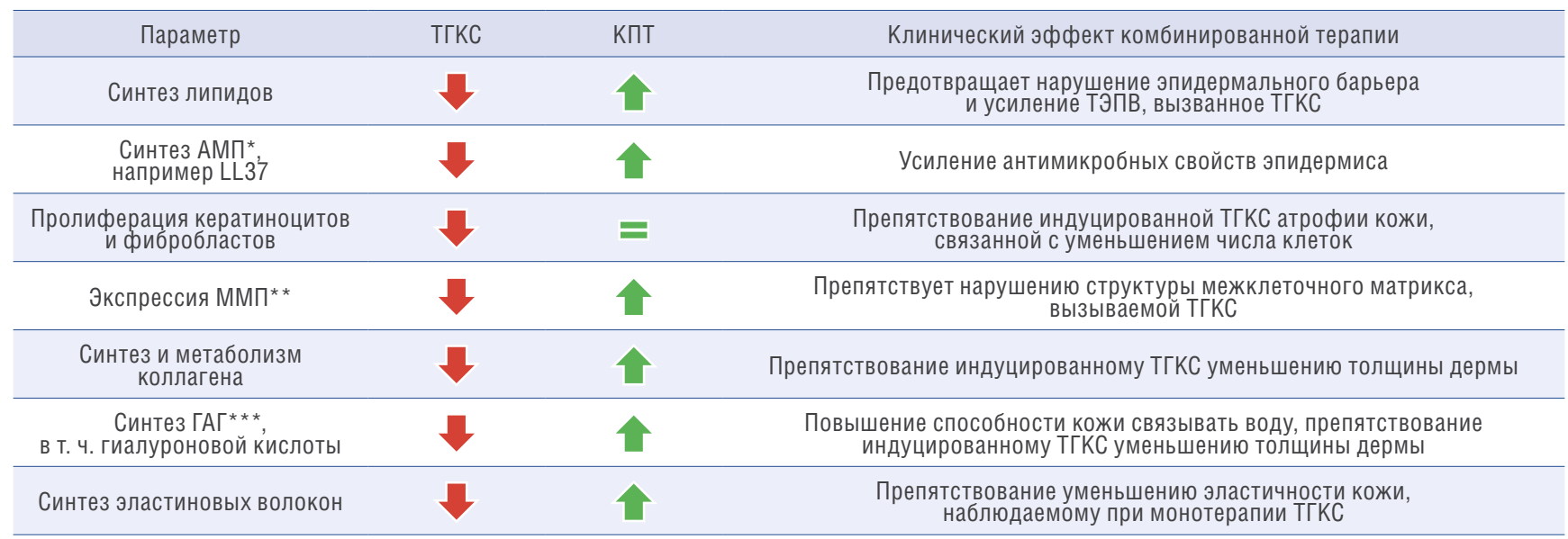

Примечание: * АМП — антимикробные пептиды; ** ММП — матриксные металлопротеиназы; *** ГАГ — гликозаминогликань

Адаптировано на основании [77], с дополнениями

Note: * АМП — antimicrobial peptides; ${ }^{* *} \mathrm{MM}$ — matrix metalloproteinases; ${ }^{* * *} Г \mathrm{~A} \Gamma$ — glycosaminoglycans

Adapted on the basis of [77], with additions

получавших системную терапию алитретиноином, проводился ирритантный тест с лаурилсульфратом натрия и липидный анализ цианоакрилатных биоптатов кожи, не было продемонстрировано какого-либо влияния указанного ретиноида на чувствительность кожи к ирритантам или профиль церамидов эпидермиса.

Витамин C - ключевой антиоксидант и метаболический регулятор; его содержание в дерме составляет 3-13 мг/100 г, в эпидермисе - 6-64 мг/100 г [82]. Он усиливает образование коллагена в дерме, т. к. является кофрактором фрерментов пролин- и лизин-гидроксилаз, стабилизирующих четвертичную структуру коллагена, а также усиливает экспрессию генов данного белка [82-85]. Витамин С усиливает диффреренцировку кератиноцитов и синтез белков рогового конверта, улучшает пространственную организацию рогового слоя, повышает содержание в кератиноцитах кератогиалиновых гранул и фрилаггрина, стимулирует синтез эпидермальных липидов и способствует их правильной организации [86-89]. Данный витамин может применяться как внутрь, так и в составе наружных средств, но доказательная база для его системного применения сегодня более качественна [82].

Витамин $\mathrm{B}_{5}$ (пантотеновая кислота) и его формапредшественник, декспантенол. Является компонентом коэнзима А, который, в свою очередь, катализирует синтез жирных кислот и сфинголипидов, необходимых для формирования эпидермального липидного барьера [90-94]. Продемонстрировано, что наружное применение препаратов пантенола и декспантенола оказывает эпителизирующий эффект, повышает гидратацию эпидермиса и способствует восстановлению эпидермального барьера; хотя точные механизмы влияния на параметры эпидермального барьера на сегодня не изучены, считается, что они связаны с гигроскопическими свойствами молекулы, ее взаимодействием с липидными компонентами межклеточного матрикса и белками рогового конверта корнеоцитов и участием в процессах синтеза эпидермальных липидов [90-94].
Никотиновая кислота и ниацинамид (объединяющий термин «витамин $\mathrm{B}_{3}$ »). Их производное, ниацин, является компонентом важнейших коферментов, участвующих в переносе водорода, - НАД и НАДФ [94]. В исследовании О. Tanno и соавт. [95], проведенном на культуре кератиноцитов человека, было продемонстрировано, что ниацинамид положительно влияет на показатели диффференцировки и усиливает биосинтез ключевых эпидермальных липидов. Подтверждением in vivo стали данные K.D. Ertel и соавт. [96], демонстрирующие улучшение показателя гидратации рогового слоя и снижение трансэпидермальной потери воды при аппликации средства, содержащего 2 \% ниацинамида. Наконец, в плацебо-контролируемом исследовании D. Mohammed и соавт. [97], в рамках которого на различные участки кожи 20 здоровых добровольцев проводились аппликации крема, содержащего 5 \% ниацинамида, было продемонстрировано, что применение указанного крема в течение 28 дней приводит к значимому уменьшению ТЭПВ, снижению содержания белка в роговом слое (что косвенно свидетельствует об улучшении когезии корнеоцитов), улучшении показателей дифференцировки корнеоцитов и снижении протеазной активности калликреина 5 (различий с плацебо для других трех сериновых протеаз получено не было).

\section{Генно-инженерные биологические препараты (ГИБП)}

К данному классу относятся рекомбинантные белки (моноклональные антитела (МАТ), цитокины и т. д.), которые в последние годы широко применяются в дерматологии.

Одним из первых, получивших наиболее востребованных классов ГИБП являются ингибиторы ФНО-а (этанерцепт, адалимумаб, инфрликсимаб, цертолизумаб, голимумаб); при этом известно, что данный цитокин является не только ключевым провоспалительным медиатором, но и участвует в фризиологических процессах в эпидермисе. На это, в частности, указывает тот фракт, что ФНО-а-конвертирующий фрермент ТАСЕ одновре- 
менно является фрактором, регулирующим параметры эпидермального барьера за счет зависимой от лиганда эпидермального фрактора роста терминальной дифференцировки кератиноцитов [98]. При этом, хотя данный класс ЛС широко применяется для лечения псориаза, у более чем 20 \% пациентов, получающих терапию ингибиторами ФНО-а, отмечаются кожные побочные эффректы; наиболее распространенным является ксероз кожных покровов, наблюдаемый у 41,9 \% пациентов, у которых отмечались кожные реакции, и свидетельствующий о дисфункции эпидермального барьера. Также отмечаются псориазиформный дерматит (30,6 \%), экзема $(23,5 \%)$, инфекции кожи $(12,5 \%)$, ладонноподошвенный пустулез (5,3 \%), псориаз (3,8 \%) и прочие НЛР [99].

Интересно, что терапия МАТ-ингибитором ИЛ12/23p40 приводила к улучшению показателей эпидермального барьера у мышей с псориазиформным дерматитом, вызванным аппликацией имиквимода (не вполне корректное, но официальное русскоязычное МНH имихимод); у данных животных наблюдалось уменьшение толщины эпидермиса и нормализация ТЭПВ на фоне супрессии экспрессии ИЛ-23р19, ИЛ-17А, ИЛ22 и гена кератина 16 [100].

C. Tawada и соавт. [101] в исследовании на культуре клеток и биоптатах эпидермиса установили, что интерфрерон-ү оказывает неблагоприятное влияние на параметры эпидермального барьера, снижая экспрессию мРНК ферментов элонгазы длинноцепочечных жирных кислот и церамид-синтазы и уменьшая таким образом синтез данных важнейших липидов эпидермиса. На основании этого K.R. Feingold [102] высказал предположение о патогенетической роли интерферона- $ү$ в дисфункции эпидермального барьера при атопическом дерматите и псориазе. В связи с этим можно предположить, что и терапия препаратами интерферона может оказывать на эпидермальный барьер схожее влияние. Несколько конфрликтуют с вышеописанными данные, полученные E. Sawada и соавт. [103], в эксперименте которых внесение смеси Тh1-цитокинов, включавшей интерферон- $\gamma$, ФНО-а и ГМ-КСФ в концентрации от 2,5 до 10 нМ, приводило к незначительному увеличению содержания церамидов в лабораторном эквиваленте человеческого эпидермиса. Однако здесь конфаундером является присутствие других цитокинов, могущих оказывать разнонаправленное с интерфероном действие.

Любопытное наблюдение было сделано Т. Yuki и соавт. [104], которые изучали влияние ФНО-а, ИЛ-4, ИЛ-17 и ИЛ-22 на параметры эпидермального барьера, связанные с плотными соединениями. Было установлено, что только ИЛ-17 вызывал снижение содержания ключевых белков плотных контактов - ZO-1, клаудина-1 и клаудина-4, а также нарушал деградацию мономеров фрилаггрина, чего не наблюдалось для других цитокинов. Ранее схожие результаты были получены в исследовании D. Gutowska-Owsiak и соавт. [105], которые продемонстрировали in vitro (в культуре кератиноцитов), что ИЛ-17 вызывает снижение содержания MPHK профилаггрина, нарушает экспрессию генов, ответственных за его процессинг, а также многочисленных генов, кодирующих белки клеточной адгезии и рогового конверта, таким образом, оказывая значительное негативное влияние на эпидермальный барьер.
В дальнейшем Q. Tan и соавт. [106] было установлено, что наблюдаемое под воздействием ИЛ-17 снижение экспрессии фрилаггрина и инволюкрина опосредуется сигнальными путями митоген-активированных протеинкиназ P38/ERK. Эти сведения дают основания полагать, что терапия ингибиторами ИЛ-17 (секукинумаб, иксекизумаб, нетакимаб) и единственным на сегодня ингибитором рецептора ИЛ-17R бродалумабом может оказать положительное влияние на параметры эпидемального барьера у пациентов с кожными заболеваниями, хотя клинических подтверждений этому на сегодня еще не опубликовано.

Негативное влияние на множество параметров эпидермального барьера со стороны Th2-цитокинов ИЛ-4 и ИЛ-13 хорошо изучено - они угнетают продукцию церамидов, антимикробных пептидов, белков корнеодесмосом, рогового конверта, плотных соединений и т. д.; считается, что эти эффректы играют важную патогенетическую роль в отношении дисфункции эпидермального барьера при атопическом дерматите [107-112]. Если ИЛ-4 играет более центральную роль, то ИЛ-13 - периферический цитокин, конституционально экспрессируемый в коже; одним из возможных механизмов негативного влияния последнего на эпидермальный барьер, по данным Y. Mitamura и соавт. [113], является периостин-зависимая стимуляция синтеза кератиноцитами ИЛ-24, который, в свою очередь, угнетает экспрессию фрилаггрина. В связи с этим есть основания полагать, что терапия новыми биологическими препаратами, неселективно ингибирующими ИЛ-4 и ИЛ-13 (дупилумаб) или селективно ИЛ-13 (тралокинумаб), будет способствовать восстановлению эпидермального барьера при атопическом дерматите.

\section{Некоторые иные классы лекарственных средств}

\section{Антагонисты рецепторов гистамина}

Гистамин - аминергический нейротрансмиттер, играющий важную роль во многих фризиологических и патологических процессах, обладает негативным влиянием на характеристики эпидермального барьера [114]. M. Gschwandtner и соавт. [115] продемонстрировали, что гистамин дозозависимо подавляет дифференцировку эпидермоцитов, экспрессию фрилаггрина, лорикрина и кератина 10, а также вызывает уменьшение толщины эпидермиса, особенно заметное в зернистом слое. Кератиноциты человека несут как H1R-, так и H2R-рецепторы гистамина, с чем связывают наблюдавшееся в экспериментах положительное влияние на эпидермальный барьер как традиционно применяемых в дерматологии антагонистов Н1-рецепторов (например, дифенгидрамин, олопатадин), так и используемых в гастроэнтерологии антагонистов Н2-рецепторов (циметидин, фрамотидин), антагонисты Н3-рецепторов подобным действием не обладают; в то же время аппликации гистамина или H2Rагониста димаприта препятствовали восстановлению эпидермального барьера у мышей $[116,117]$.

Нестероидные противовоспалительные препараты

Ряд простаноидов, в частности простагландины D2 и Е2, имеют физиологическое значение для эпидермального барьера и способствуют его восстановлению [118]. В связи с этим применение неселективных COX1/2ингибиторов может отрицательно влиять на эпидермальный барьер и замедлять его восстановление после повреждений; при этом, поскольку фризиологи- 
ческий синтез указанных простагландинов опосредуется циклооксигеназой 1-го типа, селективные COX2ингибиторы лишены подобного эфффекта [119, 120].

Тиазолидиндионы (глитазоны) - используемые для лечения сахарного диабета 2-го типа высокоафрфинные агонисты ядерных рецепторов, активируемых пролифератором пероксисом типа гамма (PPAR-ү), которые также демонстрируют положительный клинический эфффект при псориазе [121]. Продемонстрировано, что агонисты данных рецепторов стимулируют дифференцировку кератиноцитов, усиливают продукцию ключевых эпидермальных липидов, синтез и секрецию ламеллярных гранул, повышают активность глюкоцереброзидазы, стимулируют экспрессию аквапорина-3, а также уменьшают вызванное клобетазолом угнетение экспрессии фрилаггрина, инволюкрина и лорикрина, оказывая, таким образом, положительное влияние на эпидермальный барьер [122-126].

\section{Ингибиторы янус-киназ}

Янус-киназы (JAK) - цитоплазматические тирозинкиназы, от которых зависит способность факторов транскрипции STAT выполнять свою функцию активации транскрипции соответствующих генов после связывания различных цитокинов и фракторов роста с их рецепторами [127, 128]. Ингибиторы янус-киназ - новый класс лекарственных препаратов, которые могут при- меняться как системно, так и местно; причем топические ингибиторы янус-киназ в перспективе рассматриваются как возможная альтернатива ТГКС и ТИК. Было продемонстрировано, что наружное применение ингибиторов янус-киназ улучшает функцию эпидермального барьера, в частности способствует диффреренцировке кератиноцитов, повышает содержание филаггрина и естественного увлажняющего фактора и положительно влияет на морфологию эпидермиса [129, 130].

\section{Заключение}

В XXI веке наука значительно продвинулась в изучении морфологии и фризиологии человеческого эпидермиса, его барьерных свойств и их разнообразных нарушений при кожных заболеваниях и внешних воздействиях. Наружные и системные лекарственные средства, применяемые для лечения кожных заболеваний, а также заболеваний иных органов и систем, могут оказывать различное, подчас неожиданное влияние на эпидермальный барьер, улучшать или ухудшать его функцию и таким образом сказываться на течении различных дерматозов. На фоне тенденции к движению в направлении персонализированной медицины понимание этого влияния и использование данного понимания при назначении схем лечения приобретает для дерматолога все большую значимость.

\section{Литература/References}

1. Хлебникова А. Н., Петрунин Д. Д., Молочков А. В. Липиды человеческого эпидермиса (фундаментальные сведения и клиническая имплементация): Учебно-методическое пособие. М.: МОНИКИ; 2015. 71 c. [Khlebnikova A. N., Petrunin D. D., Molochkov A. V. Lipids of human epidermis. Fundamental data and clinical implementation: Study guide. Moscow:: MONIKI; 2015. 71 p. (In Russ.)]

2. Nishifuji K., Yoon J. S. The stratum corneum: the rampart of the mammalian body. Vet Dermatol. 2013 Feb;24(1):60-72.

3. Schempp C., Emde M., Wölfle U. Dermatology in the Darwin anniversary. Part 1: Evolution of the integument. J Dtsch Dermatol Ges. 2009 Sep; $7(9): 750-757$.

4. Elias P., Feingold K., Fluhr J. The skin as an organ of protection. In: Friedberg I.M., Eisen A.Z., Wolff K., Austen K.F., Goldsmith L.A., Katz S.I. (eds) Dermatology in General Medicine. New York: McGraw Hill; 2003. P. 107-118.

5. Rothman S. Physiology and biochemistry of skin. Chicago, IL: University of Chicago Press; 1954. 64 p.

6. Kligman A. M. The biology of the stratum corneum. In: Montagna W. (ed.) The Epidermis. New York: Academic Press Inc.; 1964.

7. Эрнандес Е. И., Марголина А. А., Петрухина А. О. Липидный барьер кожи и косметические средства. М.: Косметика и медицина; 2005. [Hernandez E. I., Margolina A. A., Petrukhina A. 0. Lipid barrier and cosmetic products. Moscow: Cosmetics and Medicine; 2005. (In Russ.)]

8. Kligman A. M. A brief history of how the dead stratum corneum became alive. In: Elias P.M., Feingold K.R. (eds) Skin Barrier. New York: Informa Healthcare Inc.; 2010. P. 15-24.

9. Feingold K. R. Thematic review series: skin lipids. The role of epidermal lipids in cutaneous permeability barrier homeostasis. J Lipid Res. 2007;48:2531-2546.

10. Burns D. A., Breathnach S. M., Cox N. H., Griffiths C. E. M. (eds) Rook's Textbook of Dermatology. 8th edition. Chichester: Blackwell Publishing Ltd.; 2010.
11. Elias P. M. Epidermal lipids, barrier function, and desquamation. J Invest Dermatol. 1983;80:44s-49s.

12. Lazo N. D., Meine J. G., Downing D. T. Lipids are covalently attached to rigid corneocyte protein envelopes existing predominantly as beta-sheets - a solid-state nuclear-magnetic-resonance study. J Inves Dermatol. 1995;105:296-300.

13. Swartzendruber D. C., Wertz P. W., Madison K. C., Downing D. T. Evidence that the corneocyte has a chemically bound lipid envelope. J Invest Dermatol. 1987;88:709-713.

14. Marekov L. N., Steinert P. M. Ceramides are bound to structural proteins of the human foreskin epidermal cornified cell envelope. J Biol Chem. 1998;273:17763-17770.

15. Sandhoff R. Very long chain sphingolipids: tissue expression, function and synthesisю FEBS Lett. 2010;584:1907-1913.

16. Wertz P. W. Biochemistry of human stratum corneum lipids. In: Elias P., Feingold K. (eds). Skin Barrier. New York: Informa Healthcare Inc.; 2010. P. 33-42.

17. Weerheim A., Ponec M. Determination of stratum corneum lipid profile by tape stripping in combination with high-performance thin-layer chromatography. Arch Dermatol Res. 2001;293:191-199.

18. Wertz P., Norlen L. "Confidence intervals" for the "true" lipid composition of the human skin barrier? In: Forslind B., Linberg M. (eds) Skin, Hair and Nails. Structure and Function. New York: Marcel Dekker Inc.; 2003. P. $85-106$.

19. Janssens M., van Smeden J., Gooris G. S. et al. Lamellar lipid organization and ceramide composition in the stratum corneum of patients with atopic eczema. J Invest Dermatol. 2011;131:2136-2138.

20. Long S. A., Wertz P. W., Strauss J. S. et al. Human stratum corneum polar lipids and desquamation. Arch Dermatol Res. 1985;277:284-287.

21. Elias P. M., Williams M. L., Maloney M. E. J. A. et al. Stratum corneum lipids in disorders of cornification. Steroid sulfatase and choles- 
terol sulfate in normal desquamation and the pathogenesis of recessive X-linked ichthyosis. J Clin Invest. 1984;74:1414-1421.

22. Zettersten E., Man M. Q., Sato J. et al. Recessive x-linked ichthyosis: role of cholesterol-sulfate accumulation in the barrier abnormality. J Invest Dermatol. 1998;111:784-790.

23. Bibel D. J., Aly R., Shah S., Shinefield H. R. Sphingosines: antimicrobial barriers of the skin. Acta Derm Venereol. 1993;73:407-411.

24. Wertz P. W., Downing D. T. Ceramidase activity in porcine epidermis. FEBS Lett. 1990;268:110-112.

25. Hannun Y. A., Loomis C. R., Merrill A. H. Jr. et al. Sphingosine inhibition of protein kinase $\mathrm{C}$ activity and of phorbol dibutyrate binding in vitro and in human platelets. J Biol Chem. 1986;261:12604-12609.

26. Hatta I., Ohta N., Inoue K., Yagi N. Coexistence of two domains in intercellular lipid matrix of stratum corneum. Biochim Biophys Acta. 2006;1758:1830-1836.

27. Iwai I., Han H. M., den Hollander L. et al. The human skin barrier is organized as stacked bilayers of fully extended ceramides with cholesterol molecules associated with the ceramide sphingoid moiety. J Invest Dermatol. 2012;132:2215-2225.

28. Vaena de Avalos S., Jones J. A., Hannun Y. A. Ceramides. In: Nicolaou A., Kokotos G. (eds). Bioactive Lipids. Bridgwater: The Oily Press; 2004. P. 135-167.

29. Potts R. O., Francoeur M. L. The influence of stratum corneum morphology on water permeability. J Invest Dermatol. 1991;96:495-499.

30. Steinert P. M., Cantieri J. S., Teller D. C., Lonsdale-Eccles J. D., Dale B. A. Characterization of a class of cationic proteins that specifically interact with intermediate filaments. Proc Natl Acad Sci USA. 1981;78:4097-4101.

31. Brown S. J., McLean W. H. One remarkable molecule: filaggrin. J Invest Dermatol. 2012 Mar;132(3 Pt 2):751-762.

32. Kezic S., Jakasa I. Filaggrin and Skin Barrier Function. Curr Probl Dermatol. 2016;49:1-7.

33. Sandilands A., Sutherland C., Irvine A. D., McLean W. H. Filaggrin in the frontline: role in skin barrier function and disease. J Cell Sci. 2009 May 1;122(Pt 9):1285-1294.

34. Rawlings A. V., Harding C. R. Moisturization and skin barrier function. Dermatol Ther. 2004;17(Suppl 1):43-48.

35. Janssens M., van Smeden J., Gooris G. S., Bras W., Portale G., Caspers $P$. J. et al. Increase in short-chain ceramides correlates with an altered lipid organization and decreased barrier function in atopic eczema patients. J Lipid Res. 2012;53:2755-2766.

36. Green K. J., Simpson C. L. Desmosomes: New perspectives on a classic. J Invest Dermatol. 2007;127:2499-2515.

37. Delva E., Tucker D. K., Kowalczyk A. P. The desmosome. Cold Spring Harb Perspect Biol. 2009;1:a002543.

38. Kowalczyk A. P., Green K. J. Structure, function, and regulation of desmosomes. Prog Mol Biol Transl Sci. 2013;116:95-118.

39. Johnson J. L., Najor N. A., Green K. J. Desmosomes: regulators of cellular signaling and adhesion in epidermal health and disease. Cold Spring Harb Perspect Med. 2014 Nov 3;4(11):a015297.

40. Leclerc E. A., Huchenq A., Mattiuzzo N. R., Metzger D., Chambon P., Ghyselinck N. B. et al. Corneodesmosin gene ablation induces lethal skin-barrier disruption and hair-follicle degeneration related to desmosome dysfunction. J Cell Sci. 2009;122:2699-2709.

41. Amagai M., Stanley J. R. Desmoglein as a target in skin disease and beyond. J Invest Dermatol. 2012;132:776-784.

42. Grando S. A. Pemphigus autoimmunity: Hypotheses and realities. Autoimmunity. 2012;45:7-35.

43. Rawlings A. V., Voegeli R. Stratum corneum proteases and dry skin conditions. Cell Tissue Res. 2013 Feb;351(2):217-235.

44. Niessen C. M. Tight junctions/adherens junctions: basic structure and function. J Invest Dermatol. 2007 Nov;127(11):2525-2532.

45. Schneeberger E. E., Lynch R. D. The tight junction: a multifunctional complex. Am J Physiol Cell Physiol. 2004;286:C1213-C1228.
46. Furuse M., Hata M., Furuse K., Yoshida Y., Haratake A., Sugitani $Y$. et al. Claudin-based tight junctions are crucial for the mammalian epidermal barrier: a lesson from claudin-1-deficient mice. J Cell Biol. 2002;156:1099-1111.

47. Effendy I., Maibach H. I. Detergent and skin irritation. Clin Dermatol. 1996;14(1):15-21.

48. Кутц Г. Косметические кремы и эмульсии. Состав. Получение. Методы испытаний. М.: Фирма Клавель : Косметика и медицина, 2004. 272 с. [Kutz G. Cosmetic creams and emulsions. Composition. Receipt. Test methods. Moscow: Firma Klavel: Kosmetika i Meditsina; 2004. 272 p. (In Russ.)]

49. Wolf R., Parish L. C. Effect of soaps and detergents on epidermal barrier function. Clin Dermatol. 2012;30(3):297-300.

50. Yanase K., Hatta I. Disruption of human stratum corneum lipid structure by sodium dodecyl sulphate. Int J Cosmet Sci. 2018;40(1):44-49.

51. Xian M., Wawrzyniak P., Rückert B., Duan S., Meng Y., Sokolowska M. et al. Anionic surfactants and commercial detergents decrease tight junction barrier integrity in human keratinocytes. J Allergy Clin Immunol. 2016;138(3):890-893.e9.

52. Barba C., Alonso C., Martí M., Manich A., Coderch L. Skin barrier modification with organic solvents. Biochim Biophys Acta. 2016;1858(8):1935-1943.

53. Abrams K., Harvell J. D., Shriner D., Wertz P., Maibach H., Maibach $\mathrm{H}$. I. et al. Effect of organic solvents on in vitro human skin water barrier function. J Invest Dermatol. 1993;101(4):609-613.

54. Goffin V., Letawe C., Piérard G. E. Effect of organic solvents on normal human stratum corneum: evaluation by the corneoxenometry bioassay. Dermatology. 1997;195(4):321-324.

55. Kao J. S., Fluhr J. W., Man M. Q., Fowler A. J., Hachem J. P., Crumrine D. et al. Short-term glucocorticoid treatment compromises both permeability barrier homeostasis and stratum corneum integrity: inhibition of epidermal lipid synthesis accounts for functional abnormalities. J Invest Dermatol. 2003;120(3):456-464.

56. Tadicherla S., Ross K., Shenefelt P. D., Fenske N. A. Topical corticosteroids in dermatology. J Drugs Dermatol. 2009;8(12):1093-1105.

57. Sheu H. M., Lee J. Y., Chai C. Y., Kuo K. W. Depletion of stratum corneum intercellular lipid lamellae and barrier function abnormalities after long-term topical corticosteroids. Br J Dermatol. 1997;136(6):884-890.

58. Haapasaari K. M., Risteli J., Koivukangas V., Oikarinen A. Comparison of the effect of hydrocortisone, hydrocortisone-17-butyrate and betamethasone on collagen synthesis in human skin in vivo. Acta Derm Venereol. 1995;75(4):269-271.

59. Gebhardt C., Averbeck M., Diedenhofen N., Willenberg A., Anderegg U., Sleeman J. P. et al. Dermal hyaluronan is rapidly reduced by topical treatment with glucocorticoids. J Invest Dermatol. 2010;130(1):141-149.

60. Zhang W., Watson C. E., Liu C., Williams K. J., Werth V. P. Glucocorticoids induce a near-total suppression of hyaluronan synthase mRNA in dermal fibroblasts and in osteoblasts: a molecular mechanism contributing to organ atrophy. Biochem J. 2001;349(Pt 1):91-97.

61. Saarni H., Hopsu-Havu V. K. Inhibition of acid mucopolysaccharide synthesis by hydrocortisone, hydrocortisone 17-butyrate and betamethasone 17-valerate. Br J Dermatol. 1977;97(5):505-507.

62. Carr W. W. Topical calcineurin inhibitors for atopic dermatitis: review and treatment recommendations. Pediatr Drugs. 2013;15:303-310.

63. Kyllonen H., Remitz A., Mandelin J. M., Elg P., Reitamo S. Effects of 1-year intermittent treatment with topical tacrolimus monotherapy on skin collagen synthesis in patients with atopic dermatitis. Br J Dermatol. 2004;150:1174-1181.

64. Бакулев А. Л, Кравченя С. С. Эфффективность топической терапии такролимусом при атопическом дерматите у взрослых. Вестник дерматологии и венерологии. 2012;5:106-111. [Bakulev A. L., Kravchenya S. S. Efficacy of the topical therapy with tacrolimus in case of atopic dermatitis in adults. Vestn Dermatol Venerol. 2012;5:106-111. (In Russ.)]

65. Jiráková A., Rob F., Sečníková Z., Koblová K., Džambová M., Rajská Letal. Topical corticosteroids but not calcineurin inhibitors induced atrophy after four weeks. J Biol Regul Homeost Agents. 2015;29(3):701-706. 
66. Chittock J., Brown K., Cork M. J., Danby S. G. Comparing the effect of a twice-weekly tacrolimus and betamethasone valerate dose on the subclinical epidermal barrier defect in atopic dermatitis. Acta Derm Venereol. 2015;95:653-658.

67. Hachem J. P., Houben E., Crumrine D., Man M. Q., Schurer N., Roelandt $T$. et al. Serine protease signaling of epidermal permeability barrier homeostasis. J Invest Dermatol. 2006;126:2074-2086.

68. Dähnhardt-Pfeiffer S., Dähnhardt D., Buchner M., Walter K., Proksch E., Fölster-Holst R. Comparison of effects of tacrolimus ointment and mometasone furoate cream on the epidermal barrier of patients with atopic dermatitis. J Dtsch Dermatol Ges. 2013;11(5):437-443.

69. Круглова Л. С., Петрунин Д. Д. Влияние наружной противовоспалительной терапии на морфоофункциональные характеристики эпидермального барьера. Оптимизация схем лечения атопического дерматита. Вестник дерматологии и венерологии. 2018;94(4):73-82. [Kruglova L. S., Petrunin D. D. Impact of topical anti-inflammatory therapy on morpho-functional characteristics of epidermal barrier. Optimization of atopic dermatitis treatment schedules. Vestnik Dermatologii i Venerologii. 2018;94(4):73-82. (In Russ.)]

70. Mandelin J., Remitz A., Reitamo S. Effect of oral acetylsalicylic acid on burning caused by tacrolimus ointment in patients with atopic dermatitis. Arch Dermatol. 2010;146(10):1178-1180.

71. Haussler M. R., Whitfield G. K., Kaneko I., Haussler C. A., Hsieh D., Hsieh J. C. et al. Molecular mechanisms of vitamin D action. Calcif Tissue Int. 2013;92(2):77-98.

72. Gil Á., Plaza-Diaz J., Mesa M. D. Vitamin D: Classic and Novel Actions. Ann Nutr Metab. 2018;72(2):87-95.

73. Bikle D. D. Vitamin D and the skin: Physiology and pathophysiology. Rev Endocr Metab Disord. 2012;13:3-19.

74. Bikle D. D. Vitamin D metabolism and function in the skin. Molecular and Cellular Endocrinology. 2011;347:80-89.

75. Kragballe K., Iversen L. Calcipotriol. A new topical antipsoriatic. Dermatol Clin. 1993;11(1):137-141.

76. Menter A., Korman N. J., Elmets C. A., Feldman S. R., Gelfand J. M., Gordon K. B. et al. Guidelines of care for the management of psoriasis and psoriatic arthritis. Section 3. Guidelines of care for the management and treatment of psoriasis with topical therapies. J Am Acad Dermatol. 2009;60(4):643-659.

77. Segaert S., Shear N. H., Chiricozzi A., Thaçi D., Carrascosa J. M., Young $\mathrm{H}$. et al. Optimizing Anti-Inflammatory and Immunomodulatory Effects of Corticosteroid and Vitamin D Analogue Fixed-Dose Combination Therapy. Dermatol Ther (Heidelb). 2017;7(3):265-279.

78. Norsgaard H., Kurdykowski S., Descargues P., Gonzalez T., Marstrand T., Dunstl G., Ropke M. Calcipotriol counteracts betamethasone-induced decrease in extracellular matrix components related to skin atrophy. Arch Dermatol Res. 2014;306:719-729.

79. Khalil S., Bardawil T., Stephan C. et al. Retinoids: a journey from the molecular structures and mechanisms of action to clinical uses in dermatology and adverse effects. J Dermatolog Treat. 2017;28(8):684-696.

80. Del Rosso J. Q. Clinical relevance of skin barrier changes associated with the use of oral isotretinoin: the importance of barrier repair therapy in patient management. J Drugs Dermatol. 2013;12(6):626-631.

81. Jungersted J. M., Høgh J. K., Hellgren L. I., Jemec G. B., Agner $T$. Changes in skin barrier during treatment with systemic alitretinoin: focus on skin susceptibility and stratum corneum ceramides. Arch Dermatol Res. 2010;302(9):653-656.

82. Pullar J. M., Carr A. C., Vissers M. C. M. The Roles of Vitamin C in Skin Health. Nutrients. 2017:9(8).

83. Kishimoto Y., Saito N., Kurita K., Shimokado K., Maruyama N., Ishigami A. Ascorbic acid enhances the expression of type 1 and type 4 collagen and SVCT2 in cultured human skin fibroblasts. Biochem Biophys Res Commun. 2013;430:579-584.

84. May J. M, Qu Z. C. Transport and intracellular accumulation of vitamin $C$ in endothelial cells: Relevance to collagen synthesis. Arch Biochem Biophys. 2005;434:178-186.
85. Parsons K. K., Maeda N., Yamauchi M., Banes A. J., Koller B. H. Ascorbic acid-independent synthesis of collagen in mice. Am J Physiol Endocrinol Metab. 2006;290:1131-1139.

86. Ponec M., Weerheim A., Kempenaar J., Mulder A., Gooris G. S., Bouwstra J. et al. Theformation of competent barrier lipids in reconstructed human epidermis requires the presence of vitamin $\mathrm{C} . \mathrm{J}$ Investig Dermatol. 1997; 109:348-355

87. Savini I., Catani M. V., Rossi A., Duranti G., Melino G., Avigliano $L$. Characterization of keratinocyte differentiation induced by ascorbic acid: Protein kinase $\mathrm{C}$ involvement and vitamin C homeostasis. J Investig Dermatol. 2002;118:372-379.

88. Uchida Y., Behne M., Quiec D., Elias P. M., Holleran W. M. Vitamin C stimulates sphingolipid production and markers of barrier formation in submerged human keratinocyte cultures. J Investig Dermatol. 2001;117:1307-1313.

89. Kim K. P., Shin K. O., Park K., Yun H. J., Mann S., Lee Y. M. et al. Vitamin $C$ stimulates epidermal ceramide production by regulating its metabolic enzymes. Biomol Ther. 2015;23:525-530.

90. Proksch E., Nissen H. P. Dexpanthenol enhances skin barrier repair and reduces inflammation after sodium lauryl sulphate-induced irritation. J Dermatolog Treat. 2002;13:173-178.

91. Wollina U. Zur klinischen wirksamkeit von dexpanthenol. Kosm Med. 2001;4:180-184.

92. Ebner F., Heller A., Rippke F., Tausch I. Topical use of dexpanthenol in skin disorders. Am J Clin Dermatol. 2002;3(6):427-433.

93. Proksch E., de Bony R., Trapp S., Boudon S. Topical use of dexpanthenol: a 70th anniversary article. J Dermatolog Treat. 2017;28(8):766-773.

94. Gehring W. Nicotinic acid/niacinamide and the skin. J Cosmet Dermatol. 2004 Apr;3(2):88-93

95. Tanno O., Ota Y., Kitamura N., Inoue S. Effects of niacinamide on ceramide biosynthesis and differentiation of cultured human keratinocytes. 3rd ASCS Conference Taipei, Taiwan, 1997.

96. Ertel K. D., Berge C. A., Mercurio M. G., Fowler T. J., Amburgey M. S. New facial moisturizer technology increases exfoliation without compromising barrier function. 58th Annual Meeting of the American Academy of Dermatology, San Francisco, 2000.

97. Mohammed D., Crowther J. M., Matts P. J., Hadgraft J., Lane M. E. Influence of niacinamide containing formulations on the molecular and biophysical properties of the stratum corneum. Int J Pharm. 2013;441(1-2):192-201.

98. Franzke C. W., Cobzaru C., Triantafyllopoulou A., Löffek S., Horiuchi K., Threadgill D. W. et al. Epidermal ADAM17 maintains the skin barrier by regulating EGFR ligand-dependent terminal keratinocyte differentiation. J Exp Med. 2012;209:1105-1119.

99. Segaert S., Hermans C. Clinical signs, pathophysiology and management of cutaneous side effects of anti-tumor necrosis factor agents. Am J Clin Dermatol. 2017;18(6):771-787.

100.Takahashi T., Koga Y., Kainoh M. Anti-IL-12/LL-23p40 antibody ameliorates dermatitis and skin barrier dysfunction in mice with imiquimodinduced psoriasis-like dermatitis. Eur J Pharmacol. 2018;828:26-30.

101.Tawada C., Kanoh H., Nakamura M., Mizutani Y., Fujisawa T., Banno $Y$. et al. Interferon-y decreases ceramides with long-chain fatty acids: possible involvement in atopic dermatitis and psoriasis. J Invest Dermatol. 2014;134(3):712-718.

102.Feingold K. R. The adverse effect of IFN gamma on stratum corneum structure and function in psoriasis and atopic dermatitis. J Invest Dermatol. 2014;134(3):597-600.

103.Sawada E., Yoshida N., Sugiura A., Imokawa G. Th1 cytokines accentuate but Th2 cytokines attenuate ceramide production in the stratum corneum of human epidermal equivalents: an implication for the disrupted barrier mechanism in atopic dermatitis. J Dermatol Sci. 2012;68(1):25-35.

104. Yuki T., Tobiishi M., Kusaka-Kikushima A., Ota Y., Tokura Y. Impaired Tight Junctions in Atopic Dermatitis Skin and in a Skin-Equivalent Model Treated with Interleukin-17. PLOS One. 2016;11(9):e0161759.

105.Gutowska-Owsiak D., Schaupp A. L., Salimi M., Selvakumar T. A., McPherson T., Taylor S. et al. IL-17 downregulates filaggrin and affects 
keratinocyte expression of genes associated with cellular adhesion. Exp Dermatol. 2012;21(2):104-110.

106.Tan Q., Yang H., Liu E., Wang H. P38/ERK MAPK signaling pathways are involved in the regulation of filaggrin and involucrin by IL-17. Mol Med Rep. 2017;16(6):8863-8867.

107. Hatano Y., Terashi H., Arakawa S., Katagiri K. Interleukin-4 suppresses the enhancement of ceramide synthesis and cutaneous permeability barrier functions induced by tumor necrosis factor-alpha and interferon-gamma in human epidermis. J Invest Dermatol. 2005;124(4):786-792.

108. Totsuka A., Omori-Miyake M., Kawashima M., Yagi J., Tsunemi Y. Expression of keratin 1, keratin 10, desmoglein 1 and desmocollin 1 in the epidermis: possible downregulation by interleukin-4 and interleukin-13 in atopic dermatitis. Eur J Dermatol. 2017;27(3):247-253.

109.Omori-Miyake M., Yamashita M., Tsunemi Y., Kawashima M., Yagi J. In vitro assessment of IL-4- or IL-13-mediated changes in the structural components of keratinocytes in mice and humans. J Invest Dermatol. 2014;134(5):1342-1350.

110.Bao L., Mohan G. C., Alexander J. B., Doo C., Shen K., Bao J. et al. A molecular mechanism for IL-4 suppression of Ioricrin transcription in epidermal keratinocytes: implication for atopic dermatitis pathogenesis. Innate Immun. 2017;23(8):641-647.

111.Hönzke S., Wallmeyer L., Ostrowski A., Radbruch M., Mundhenk L., Schäfer-Korting M. et al. Influence of Th2 Cytokines on the Cornified Envelope, Tight Junction Proteins, and B-Defensins in Filaggrin-Deficient Skin Equivalents. J Invest Dermatol. 2016;136(3):631-639.

112.Strid J., McLean W. H. I., Irvine A. D. Too Much, Too Little or Just Enough: A Goldilocks Effect for IL-13 and Skin Barrier Regulation? J Invest Dermatol. 2016;136(3):561-564.

113.Mitamura Y., Nunomura S., Nanri Y., Ogawa M., Yoshihara T., Masuoka M. et al. The IL-13/periostin/L-24 pathway causes epidermal barrier dysfunction in allergic skin inflammation. Allergy. 2018;73(9):1881-1891.

114.De Benedetto A., Yoshida T., Fridy S., Park J. E., Kuo I. H., Beck L. A. Histamine and Skin Barrier: Are Histamine Antagonists Useful for the Prevention or Treatment of Atopic Dermatitis? J Clin Med. 2015;4(4):741-755.

115.Gschwandtner M., Mildner M., Mlitz V., Gruber F., Eckhart L., Werfel T. et al. Histamine suppresses epidermal keratinocyte differentiation and impairs skin barrier function in a human skin model. Allergy. 2013;68:37-47.

116. Ashida Y., Denda M., Hirao T. Histamine $\mathrm{H} 1$ and $\mathrm{H} 2$ receptor antagonists accelerate skin barrier repair and prevent epidermal hyperplasia induced by barrier disruption in a dry environment. J Invest Dermatol. 2001;116(2):261-265.

117.Lin T. K., Man M. Q., Santiago J. L., Park K., Roelandt T., Oda Y. et al. Topical antihistamines display potent anti-inflammatory activity linked in part to enhanced permeability barrier function. J Invest Dermatol. 2013;133(2):469-478.
118. Honma Y., Arai I., Hashimoto Y., Futaki N., Sugimoto M., Tanaka M. et al. Prostaglandin D2 and prostaglandin E2 accelerate the recovery of cutaneous barrier disruption induced by mechanical scratching in mice. Eur J Pharmacol. 2005;518(1):56-62.

119.Honma Y., Arai I., Sakurai T., Futaki N., Hashimoto Y., Sugimoto $M$. et al. Effects of indomethacin and dexamethasone on mechanical scratching-induced cutaneous barrier disruption in mice. Exp Dermatol. 2006;15(7):501-508.

120.Honma Y., Arai I., Futaki N., Hashimoto Y., Sugimoto M., Sakurai T. et al. Cyclooxygenase-1 inhibition delays recovery of the cutaneous barrier disruption caused by mechanical scratching in mice. Br J Dermatol. 2007;156(6):1178-1187.

121.Malhotra A., Shafiq N., Rajagopalan S., Dogra S., Malhotra S. Thiazolidinediones for plaque psoriasis: a systematic review and meta-analysis. Evid Based Med. 2012;17(6):171-176.

122.Demerjian M., Choi E. H., Man M. Q., Chang S., Elias P. M., Feingold K. R. Activators of PPARs and LXR decrease the adverse effects of exogenous glucocorticoids on the epidermis. Exp Dermatol. 2009;18(7):643-649.

123.Man M. Q., Choi E. H., Schmuth M., Crumrine D., Uchida Y., Elias $P$. M. et al. Basis for improved permeability barrier homeostasis induced by PPAR and LXR activators: liposensors stimulate lipid synthesis, lamellar body secretion, and post-secretory lipid processing. J Invest Dermatol. 2006;126(2):386-392.

124.Jiang Y. J., Kim P., Lu Y. F., Feingold K. R. PPARgamma activators stimulate aquaporin 3 expression in keratinocytes/epidermis. Exp Dermatol. 2011;20(7):595-599.

125.Ramot Y., Mastrofrancesco A., Camera E., Desreumaux P., Paus R., Picardo M. The role of PPARy-mediated signalling in skin biology and pathology: new targets and opportunities for clinical dermatology. Exp Dermatol. 2015;24(4):245-251.

126.Mao-Qiang M., Fowler A. J., Schmuth M., Lau P., Chang S., Brown B. E. et al. Peroxisome-proliferator-activated receptor (PPAR)-gamma activation stimulates keratinocyte differentiation. J Invest Dermatol. 2004;123(2):305-312.

127.Shreberk-Hassidim R., Ramot Y., Zlotogorski A. Janus kinase inhibitors in dermatology: A systematic review. J Am Acad Dermatol. 2017;76(4):745-753.

128.Damsky W., King B. A. JAK inhibitors in dermatology: The promise of a new drug class. J Am Acad Dermatol. 2017;76(4):736-744.

129.Clarysse K., Pfaff C. M., Marquardt Y., Huth L., Kortekaas Krohn I., Kluwig D. et al. JAK1/3 inhibition preserves epidermal morphology in full-thickness 3D skin models of atopic dermatitis and psoriasis. J Eur Acad Dermatol Venereol. 2018 Oct 25 [Epub ahead of print].

130.Amano W., Nakajima S., Kunugi H., Numata Y., Kitoh A., Egawa $\mathrm{G}$. et al. The Janus kinase inhibitor JTE-052 improves skin barrier function through suppressing signal transducer and activator of transcription 3 signaling. J Allergy Clin Immunol. 2015;136(3):667-677.

\section{Информация об авторе}

Дмитрий Дмитриевич Петрунин - к.м.н., менеджер по научно-медицинским вопросам 000 «ЛЕО Фармасьютикал Продактс»; e-mail: prof.preobrazhenskii@gmail.com

\section{Information about the author}

Dmitry D. Petrunin - Cand. Sci. (Med.), Medical \& Scientific Affairs Manager, LEO Pharmaceutical Products, LLC; e-mail: prof.preobrazhenskii@gmail.com 